\title{
A polarização da qualidade do emprego na agricultura brasileira no período $1992-2004^{1}$

\author{
Otávio Valentim Balsadi ${ }^{2}$
} \\ José Francisco Graziano da Silva ${ }^{3}$
}

\begin{abstract}
Resumo
O artigo analisou a polarização dentro do mercado de trabalho assalariado na agricultura brasileira no período 1992-2004. Para a análise, foram selecionados vários indicadores e construído um Índice de Qualidade do Emprego (IQE) para os empregados permanentes e temporários, segundo o local de moradia, com base nos dados da Pesquisa Nacional por Amostra de Domicílios (PNAD). A polarização da qualidade do emprego agrícola mostrou-se evidente no grau de formalidade do trabalho, nos rendimentos médios mensais recebidos, no nível educacional e nos auxílios recebidos pelos empregados. Em geral, a melhor qualidade do emprego foi verificada para os empregados permanentes das principais commodities nas regiões de agricultura mais dinâmica.
\end{abstract}

Palavras-chave: Mercado de trabalho; Trabalho assalariado; Polarização; Agricultura; Brasil.

\section{Abstract \\ The polarization of the employment quality in Brazilian agriculture: 1992-2004 period}

The article analyzed the polarization in the salaried labor market in Brazilian agriculture over 19922004. For the analysis, some indicators was selected and an Employment Index Quality (EQI) was built for the permanent and temporary workers resident in rural and urban areas of Brazil, based on the National Household Sample Survey (PNAD) data. The results showed that polarization of the agricultural employment quality was present in the employment degree of formality, main work income, employees' educational level and benefits received by the employees. Also, the data showed

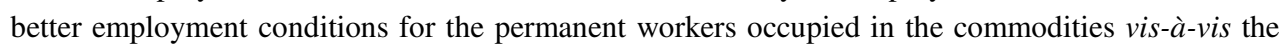
traditional domestic ones.

Key words: Labor market; Salaried work; Polarization; Agriculture; Brazil.

JEL J21, J23, J43.

\section{Introdução}

Uma consulta minimamente atenta à literatura especializada mostra que, apesar da relevância do tema, há poucos estudos sobre o mercado de trabalho na agricultura brasileira, particularmente no período mais recente. Entre eles, podem ser citados os de Balsadi (2006b), Ferreira et al. (2006), Rezende (2005), Ferreira Filho (2004), Belik et al. (2003) e Balsadi et al. (2002). Recentes estudos sobre o

(1) Trabalho recebido em fevereiro de 2007 e aprovado em novembro de 2007.

(2) Pesquisador da Empresa Brasileira de Pesquisa Agropecuária (Embrapa), Brasília, DF, Brasil. E-mail: otavio.balsadi@embrapa.br.

(3) Professor do Instituto de Economia da Universidade Estadual de Campinas (Unicamp. IE), Campinas, SP, Brasil. E-mail: jose.grazianodasilva@fao.org. 
desempenho da agricultura e do agronegócio, como os de Contini et al. (2006), Mueller (2005), Brandão, Rezende e Marques (2005), Gasques et al. (2004a, 2004b) dedicaram escasso espaço para o tema das ocupações e do emprego agrícola.

Vale dizer, ainda, que os importantes estudos do Projeto Rurbano, coordenados pelo Instituto de Economia da Unicamp, estiveram concentrados na análise da população economicamente ativa (PEA) rural não metropolitana, pois tinham como um dos objetivos centrais mostrar que, cada vez mais, as atividades não agrícolas, desenvolvidas tanto nos espaços urbanos quanto nos rurais, respondem pelas ocupações e pela renda de parcelas crescentes da população rural brasileira (Campanhola; Graziano da Silva, 2000).

Com o presente estudo, pretende-se contribuir para a análise da população economicamente ativa, rural e urbana, ocupada total ou parcialmente na agricultura no período recente. O intuito é fazer essa análise para a categoria específica dos empregados no período 1992-2004, com foco no mercado de trabalho assalariado agrícola e com destaque para as evoluções diferenciadas que ocorreram entre as Grandes Regiões e entre as principais culturas.

Segundo dados da PNAD, os empregados, que constituem a fatia do mercado de trabalho assalariado, representaram cerca de $29,0 \%$ do total de ocupados na agricultura, em 2004. Nas regiões Centro-Oeste e Sudeste, as participações dessa categoria superaram os 40,0\% e no Norte Urbano, tal participação alcançou os $34,0 \%$. Vale dizer que, desde 2001, os empregados (permanentes e temporários) são a categoria majoritária de ocupados na agricultura brasileira.

Em função do exposto, o objetivo principal do presente artigo é apresentar alguns indicadores de qualidade do emprego na agricultura brasileira no período recente. Mais especificamente, pretende-se mostrar que os movimentos gerais da agricultura tiveram como resultado o aumento das discrepâncias na qualidade do emprego agrícola entre as diferentes categorias de empregados, reforçando uma tendência de polarização dentro do mercado de trabalho assalariado agrícola.

Para isso, serão utilizados os seguintes indicadores: empregados com carteira assinada e empregados com contribuição para a Previdência Social, na dimensão do grau de formalidade; empregados que recebiam mais de um salário mínimo por mês no trabalho principal e rendimento médio mensal dos empregados no trabalho principal, na dimensão dos rendimentos; empregados com oito anos ou mais de estudo, na dimensão do nível de escolaridade; e índice parcial de auxílios recebidos pelos empregados. Também será construído um ranking para o Índice de Qualidade do Emprego (IQE), de modo a obter-se uma ordenação das melhores e piores situações de emprego na agricultura brasileira. 
A polarização da qualidade do emprego na agricultura brasileira no período 1992-2004

O que se pretende mostrar é que há fortes contrastes entre a qualidade do emprego dos empregados permanentes e dos empregados temporários. Isto é, os empregados pertencentes ao segmento mais estruturado do mercado de trabalho assalariado agrícola foram os principais beneficiários pelo desempenho da agricultura brasileira no período 1992-2004. A polarização da qualidade do emprego pode ser observada tanto no nível agregado do Brasil quanto nas desagregações por Grandes Regiões e culturas selecionadas. E mais: além da polarização dentro dos agregados, também houve esse movimento entre as regiões e entre as culturas selecionadas. Como poderá ser visto, de forma geral e com raras exceções, os maiores benefícios foram para os empregados permanentes das regiões de agricultura mais dinâmica e ocupados nas principais commodities.

O artigo está estruturado da seguinte forma: na seção seguinte, é feita uma breve discussão acerca da temática da polarização no mercado de trabalho no Brasil, na qual destacam-se os estudos sobre o mercado de trabalho urbano. Com esse pano de fundo, faz-se, na seqüência, uma análise da polarização da qualidade do emprego agrícola entre os empregados permanentes e temporários, segundo as Grandes Regiões e algumas culturas, levando-se em consideração o local de moradia dos mesmos (rural e urbano). Após a discussão da polarização no grau de formalidade do emprego, nos rendimentos recebidos, no nível de escolaridade e nos auxílios recebidos pelos empregados, há uma seção dedicada ao ranking do Índice de Qualidade do Emprego (IQE). Para concluir, são apresentadas algumas considerações finais.

\section{0 tema da polarização no mercado de trabalho brasileiro}

As discussões sobre a polarização no mercado de trabalho brasileiro podem ser remontadas ao início dos anos 1990, embora ainda sem as suas principais caracterizações. Um primeiro ponto a destacar é que elas surgiram, também, no bojo das análises sobre os efeitos da reestruturação produtiva no mundo do trabalho, particularmente nos setores da indústria de transformação e dos serviços especializados, e tinham como foco principal o mercado de trabalho urbano (não raro com um olhar mais específico sobre as regiões metropolitanas brasileiras). Quanto ao mercado de trabalho agrícola, em particular, os estudos e análises eram e ainda são absolutamente raros.

Essas discussões também foram alimentadas por outros temas emergentes na época, como os novos rumos da chamada sociedade da informação e o papel do conhecimento na nova economia que se afirmava com a globalização e com os enormes avanços no setor da telemática. Os pressupostos do debate eram que, por um lado, a reestruturação produtiva acarretava um crescimento acelerado do setor de serviços, em detrimento da perda de importância da indústria de transformação, e que, por outro lado, a polarização do mercado de trabalho tenderia a aumentar 
com o desenvolvimento da sociedade da informação em função dos diferenciais por qualificação e por nível de escolaridade (trabalhadores muito qualificados versus trabalhadores pouco qualificados) nos novos postos de trabalho gerados. Com isso, o principal efeito seria uma polarização na estrutura ocupacional e nos salários recebidos, além de uma perda da qualidade dos empregos (ou uma precarização), pois seriam criados mais empregos nas categorias ocupacionais de pouca qualificação comparativamente com os empregos criados para os trabalhadores mais qualificados e especializados.

Em um importante estudo organizado pelo Centro Brasileiro de Análises e Pesquisas na primeira metade dos anos 1990, é possível perceber o tema da polarização nas análises de dois especialistas sobre mercado de trabalho (CEBRAP, 1994). Ao analisar as principais informações sobre o mercado de trabalho na década de 1980 e início dos anos 1990, Edward Amadeo diz: "Há duas coisas acontecendo: de um lado, uma redução do tamanho do setor moderno e um crescimento do setor tradicional e, de outro, uma intensificação das diferenças qualitativas. É para isso que quero chamar a atenção. Que diferenças são essas? Os trabalhadores que permaneceram empregados no setor industrial passaram a estabelecer um tipo de relacionamento com as empresas muito diferente do que tinham antes. Por quê? Porque, para esses trabalhadores, as empresas passaram a incorporar um tipo de atitude e um tipo de comportamento muito diferentes do que tinham antes. Esses sim são a nata, o núcleo do setor empregado que merece um tipo de tratamento diferenciado quando se vai entrar num período de competitividade com base na qualidade dos recursos humanos. Na minha opinião, houve uma acentuação da heterogeneidade do mercado de trabalho, tanto do ponto de vista quantitativo, com o enxugamento do setor formal e ampliação do setor informal, quanto com a ampliação das diferenças qualitativas" (CEBRAP, 1994, p. 31).

Cláudio Dedecca, observando os princípios que nortearam a reestruturação industrial nas décadas posteriores à de 1970 e seus efeitos sobre o mercado de trabalho, planteia o seguinte questionamento: como as empresas realizaram esse processo? Nas palavras do autor: "Em primeiro lugar, introduzindo novas tecnologias e novos métodos organizacionais. Em segundo lugar, tentando fugir do controle sindical e buscando romper os contratos coletivos de trabalho. Em terceiro lugar, fechando e relocalizando plantas produtivas com o objetivo de criar uma relação de trabalho nova que fugisse daquele padrão anterior. Pois bem, quais foram os efeitos desse processo? Eu elencaria alguns, apesar de serem muito mais complexos e extensos. Em primeiro lugar, verifica-se um crescimento substantivo da heterogeneidade do mercado de trabalho nos países desenvolvidos, marcada pela precarização das relações de trabalho, pela polarização do mercado de trabalho e pela informalização" (CEBRAP, 1994, p. 42). 
Em alguns estudos mais recentes, a expressão polarização do mercado de trabalho tem sido utilizada, predominantemente, para identificar um fenômeno que coloca em extremos opostos dois núcleos de trabalhadores: um núcleo mais ou menos estável e com alta qualificação profissional e um outro núcleo, bem maior, muito instável e composto de trabalhadores de baixa qualificação e com uma qualidade do trabalho muito precária ${ }^{4}$. Dessa forma, amplia-se o fosso entre os setores ditos formais, nos quais os empregados estão relativamente bem protegidos, do ponto de vista da legislação trabalhista e da seguridade social, e os setores informais, nos quais os empregados não possuem garantias mínimas e auferem os menores salários.

Analisando a reestruturação produtiva e a polarização do mercado de trabalho em Paranaguá, município portuário do Estado do Paraná, Godoy (2000) concluiu que a reestruturação econômica ocorrida a partir dos anos 1970 acelerou a formação de dois segmentos no mercado de trabalho: um que se encontra em melhores condições de trabalho (maior predominância de trabalho permanente e formal), em grande parte ligado direta ou indiretamente ao porto, e outro constituído pela maioria de trabalhadores desvinculados das atividades portuárias, que tendem a ter piores condições de trabalho, ou seja, trabalho temporário e informal. Com isso, houve uma diminuição do trabalho direto e a formação de um segmento vinculado à nova dinâmica internacional com melhores condições de trabalho e a formação de outro segmento alijado do processo e com piores condições de trabalho.

Araújo (2001), ao estudar os efeitos das transformações produtivas e das mudanças na estrutura ocupacional da Região Metropolitana de São Paulo (RMSP) nas décadas de 1980 e 1990, notou que as alterações no mercado de trabalho acirraram as históricas dificuldades de inserção dos trabalhadores na estrutura ocupacional da região, sendo que a evolução das ocupações no setor de serviços aprofundou a heterogeneidade, indicando uma tendência à polarização do mercado de trabalho, com graves conseqüências sociais ${ }^{5}$. Ainda segundo a autora, as principais alterações ocorridas no mercado de trabalho da Região Metropolitana

(4) Um estudo que traz outra abordagem é o de Scorzafave e Menezes-Filho (2005). A preocupação dos autores foi construir uma medida da polarização do trabalho com enfoque na condição dos indivíduos na unidade domiciliar. Assim, a atenção foi dada aos domicílios sem trabalho (ou seja, no qual todos os membros estão na condição de não-trabalho) vis-à-vis os domicílios com trabalho. Por meio de modelos econométricos, os autores analisaram algumas características individuais e do próprio domicílio que podem influenciar as situações de nãotrabalho e de trabalho, jogando luz sobre fatores explicativos da polarização observada para o total da população brasileira.

(5) "A natureza excludente das transformações em curso sinaliza para a tendência, em formação, de uma estrutura ocupacional polarizada, caracterizada pelas altas taxas de crescimento, em termos relativos, das ocupações em serviços auxiliares e produtivos, que contém parcela significativa das ocupações que exigem ensino médio e superior, e, em termos absolutos, dos postos de trabalho em prestação de serviços pessoais, com baixas qualificação e remuneração" (Araújo, 2001, p. 3). 
de São Paulo no período 1988-1999 foram as seguintes: redução da participação dos ocupados no setor industrial, de 32,0\% para 20,0\%; ampliação da participação dos ocupados no setor de serviços, de $60,0 \%$ para $74,0 \%$, com destaque para o crescimento dos ocupados nos serviços relacionados à produção e nos serviços pessoais e domésticos; perda de capacidade de geração de ocupações assalariadas com carteira de trabalho assinada.

Tendo como tema principal as crescentes tensões urbanas nas regiões metropolitanas do mundo globalizado, Soja (2001) descreveu os efeitos da reestruturação industrial pós-fordista sobre a paisagem urbana: mudanças radicais na estrutura, na composição e na organização espacial dos mercados de trabalho, contribuindo para uma maior fragmentação, desigualdade e polarização. "Este novo mercado de trabalho marcadamente polarizado, freqüentemente preenchido por nichos étnicos especializados, é mais proeminente nos EUA, mas também é parte da nova economia urbana na maioria dos países industriais avançados. Nas cidades que não possuem uma faixa de classe média destacada e significativa nos seus mercados de trabalho, a polarização é tipicamente intensificada" (Araújo, 2001, p. 5).

Tapia e Gomes (2002), ao discutirem a integração européia e as novas políticas de regulação social, observaram uma crescente interdependência entre as políticas de proteção social, as políticas para o mercado de trabalho e as principais dimensões da orientação macroeconômica adotadas no plano comunitário. Segundo os autores, é preciso estudar os efeitos combinados das decisões adotadas no âmbito das políticas sociais e do mercado de trabalho, "pois seus resultados podem ter efeitos perversos não desejáveis, como exemplificam os casos em que há uma polarização do mercado de trabalho entre um núcleo estável de trabalhadores qualificados e uma grande periferia constituída por trabalhadores de baixa qualificação" (Araújo, 2001, p. 5).

Estudando as principais características da população economicamente ativa feminina nos anos 1990, com destaque para a parcela ocupada no emprego doméstico, Andrade (2004) concluiu que há uma forte clivagem de cor/raça do mercado de trabalho, que pode também ser uma forma de polarização. De acordo com a autora, o emprego doméstico, uma das mais precárias posições na estrutura de ocupações, tanto do ponto de vista sócio-ocupacional quanto dos rendimentos e da proteção social, incorporou $19,0 \%$ da variação da PEA branca das mulheres casadas e $48,0 \%$ no caso das chefes de família negras.

Ao debater o problema do desemprego nas regiões metropolitanas, em geral, e na de São Paulo, em particular, Dedecca (2006) ponderou que a introdução de novas tecnologias e/ou de novas técnicas gerenciais, no âmbito da reestruturação produtiva, teve como resultado o aumento do desemprego e da 
A polarização da qualidade do emprego na agricultura brasileira no período 1992-2004

precarização das relações de trabalho. Segundo o autor, "as ocupações semiqualificadas da indústria e de certos segmentos dos serviços (como os bancários) foram as mais atingidas por esse processo, o que levou ao desemprego muitas pessoas relativamente escolarizadas e qualificadas, em faixas etárias avançadas e com experiência de trabalho. Entretanto, tais credenciais não se adequavam aos novos postos de trabalho que foram criados, em sua maioria com baixas exigências de qualificação - como vigias, pessoal de limpeza e manutenção de edifícios, vendedores no comércio varejista (inclusive ambulantes), atendentes em vários segmentos do setor de serviços, etc. Tampouco se adequavam aos postos mais qualificados que também foram gerados nos últimos anos, notadamente nos serviços especializados e auxiliares às empresas, nas instituições financeiras, etc. Pode-se dizer que ocorreu uma espécie de polarização do mercado de trabalho, no sentido de que os postos de trabalho criados, além de serem em menor número do que os destruídos, concentravam-se (em maior medida) em ocupações com poucas (qualificações) ou, em menor medida, com elevadas exigências de qualificação" (Araújo, 2001, p. 2).

Nesse resgate sobre o tema da polarização no mercado de trabalho, podese perceber que esse fenômeno está intimamente ligado com o aumento da heterogeneidade e com a desestruturação do mercado de trabalho em geral, medida pelos indicadores de informalização, de precarização das relações de trabalho, de aumento das desigualdades, entre outros.

Também é possível notar que a polarização é aprofundada pela diferença no perfil de trabalhador exigido pelas atividades econômicas mais dinâmicas (não raro associadas ao mercado externo) e pelas atividades mais tradicionais. Isso ocorre porque, entre outros motivos, as atividades econômicas mais dinâmicas e modernizadas foram as que mais introduziram as inovações tecnológicas e gerenciais requeridas pelo processo de reestruturação produtiva. E, se tais atividades estavam articuladas ao mercado internacional, não se pode deixar de considerar as recentes exigências de certificações que comprovem o respeito aos direitos humanos, aos direitos trabalhistas e à preservação e conservação do meio ambiente, que as pressionam para oferecerem melhores condições de trabalho e emprego.

Uma terceira observação seria no sentido de que, para vários especialistas, juntamente com a maior instabilidade e o aumento expressivo do desemprego, a crescente polarização é também apontada como um dos principais problemas do mercado de trabalho. Com o agravante de que é comum observar-se, no grupo de trabalhadores menos qualificados, pessoas com nível de escolaridade relativamente alto (ou seja, mesmo com mais educação, as pessoas estão trabalhando em atividades que exigem baixa qualificação, as quais são as que mais crescem no mercado de trabalho). 
Dadas as nuances e a escassez de estudos sobre o mercado de trabalho agrícola, a polarização da qualidade do emprego ainda será tratada como um tema de pesquisa que merecerá mais atenção no futuro próximo. No entanto, independentemente da raridade de estudos, os dados captados pela PNAD e tabulados no presente estudo são bastante elucidativos para mostrar que o fenômeno da polarização, perceptível por estudiosos do mercado de trabalho urbano já há algum tempo, também está presente no mercado de trabalho assalariado agrícola, como será visto na seqüência.

\section{A polarização no mercado de trabalho assalariado agrícola}

Antes da análise propriamente dita, é importante ressaltar o seguinte: diferentemente dos estudos acima mencionados, que foram orientados para o mercado de trabalho urbano e que analisaram todas as categorias de ocupados, com ênfase na comparação entre a evolução de dois setores, no caso a indústria de transformação e os serviços, no presente estudo, os dados estão circunscritos a apenas um setor: a agricultura brasileira. Também vale dizer que as comparações estão restritas aos ocupados em uma mesma posição na ocupação, no caso os empregados (permanentes e temporários).

Por isso, conforme já assinalado, a polarização da qualidade do emprego será explorada no contexto geral de Brasil, suas Grandes Regiões e algumas culturas selecionadas. E somente para o mercado de trabalho assalariado e não para o mercado agrícola em geral, que também inclui as demais categorias de ocupados (empregadores, conta própria, membros da família não remunerados e trabalhadores na produção para o próprio consumo). Em função do exposto, obviamente, os resultados terão um alcance mais limitado do que os obtidos nos estudos sobre o mercado de trabalho urbano. No entanto, cumprem um importante papel ao "descortinarem" um tema da maior relevância para futuros estudos acerca do mercado de trabalho na agricultura brasileira.

Algumas notas metodológicas também se fazem necessárias para uma melhor compreensão do texto. Primeiramente, de acordo com IBGE (2004), empregado é a pessoa que trabalha para um empregador (pessoa física ou jurídica), geralmente obrigando-se ao cumprimento de uma jornada de trabalho e recebendo em contrapartida uma remuneração em dinheiro, mercadorias, produtos ou benefícios (moradia, alimentação, roupas, etc.). Em função da sua inserção, os empregados são classificados em temporários e permanentes.

Ainda segundo o IBGE, o empregado é considerado temporário quando o contrato ou acordo (verbal ou escrito) de trabalho tem um término estabelecido, que pode ser, ou não, renovado. Ou seja, o empregado que foi contratado por tempo determinado ou para executar um trabalho específico cuja conclusão acarreta o encerramento do contrato ou acordo de trabalho. $\mathrm{O}$ trabalhador 
temporário pode, de acordo com a região, receber uma das seguintes denominações: bóia-fria, volante, calunga, turmeiro, peão de trecho, clandestino, etc. Em contraposição, o empregado é considerado permanente quando o contrato ou acordo (verbal ou escrito) de trabalho não tem um término estabelecido.

Os rendimentos médios dos empregados foram corrigidos para dezembro de 2005, por meio do Índice Nacional de Preços ao Consumidor (INPC), do IBGE. A escolha do índice de preços deu-se pelo fato de ele ser obtido para famílias com renda na faixa de um a oito salários mínimos, o que é muito mais próximo da realidade das famílias dos empregados na agricultura brasileira. Para a correção dos rendimentos médios, foi utilizado o mesmo método descrito em Hoffmann e Kageyama (2005).

Dado o número de casos presentes nas amostras das PNADs, os indicadores selecionados e o IQE foram calculados para a atividade agrícola como um todo para Brasil e Grandes Regiões. A Tabela 1 mostra o número de casos que a PNAD captou para os empregados permanentes e temporários nos anos selecionados para análise.

Tabela 1

Número de casos nas amostras da PNAD para empregado permanente e temporário, segundo a área Brasil e Grandes Regiões, 1992-2004

\begin{tabular}{|c|c|c|c|c|c|c|c|c|c|c|}
\hline \multirow{3}{*}{$\begin{array}{l}\text { Brasil e } \\
\text { Grandes } \\
\text { Regiões }\end{array}$} & \multicolumn{10}{|c|}{ Empregado Permanente } \\
\hline & \multicolumn{5}{|c|}{ Urbano } & \multicolumn{5}{|c|}{ Rural } \\
\hline & 1992 & 1995 & 1998 & 2001 & 2004 & 1992 & 1995 & 1998 & 2001 & 2004 \\
\hline Centro-Oeste & 290 & 322 & 275 & 320 & 306 & 666 & 681 & 683 & 538 & 592 \\
\hline Nordeste & 479 & 502 & 289 & 403 & 445 & 1.175 & 1.034 & 858 & 954 & 898 \\
\hline Norte Urbano & 67 & 89 & 76 & 139 & 128 & - & - & - & - & - \\
\hline Sudeste & 695 & 616 & 563 & 488 & 539 & 1.227 & 1.133 & 1.006 & 912 & 774 \\
\hline Sul & 191 & 205 & 163 & 161 & 175 & 462 & 423 & 381 & 361 & 355 \\
\hline Total de Brasil & 1.722 & 1.734 & 1.366 & 1.511 & 1.593 & 3.530 & 3.271 & 2.928 & 2.765 & 2.619 \\
\hline \multirow{3}{*}{$\begin{array}{l}\text { Brasil e } \\
\text { Grandes } \\
\text { Regiões }\end{array}$} & \multicolumn{10}{|c|}{ Empregado Temporário } \\
\hline & \multicolumn{5}{|c|}{ Urbano } & \multicolumn{5}{|c|}{ Rural } \\
\hline & 1992 & 1995 & 1998 & 2001 & 2004 & 1992 & 1995 & 1998 & 2001 & 2004 \\
\hline Centro-Oeste & 310 & 306 & 206 & 283 & 259 & 213 & 165 & 144 & 124 & 161 \\
\hline Nordeste & 488 & 472 & 355 & 645 & 774 & 1.331 & 1.209 & 1.121 & 1.266 & 1.540 \\
\hline Norte Urbano & 136 & 129 & 153 & 284 & 300 & - & - & - & - & - \\
\hline Sudeste & 722 & 566 & 460 & 464 & 705 & 481 & 546 & 521 & 515 & 504 \\
\hline Sul & 284 & 229 & 194 & 162 & 196 & 240 & 220 & 210 & 160 & 179 \\
\hline Total de Brasil & 1.940 & 1.702 & 1.368 & 1.838 & 2.234 & 2.265 & 2.140 & 1.996 & 2.065 & 2.384 \\
\hline
\end{tabular}

Fonte: Elaboração dos autores a partir dos microdados da PNAD.

Como situação urbana consideram-se as áreas correspondentes às cidades (sedes municipais), às vilas e sedes distritais e às áreas urbanas não urbanizadas. A situação rural abrange toda a área situada fora desses limites. Tal critério também 
é utilizado na classificação das populações urbana e rural. Tradicionalmente, a agregação oficial dos dados em urbano e rural segue o que é definido pelos próprios municípios, sendo seguido pelas estatísticas do IBGE.

Apenas para algumas culturas, mesmo assim somente para o total de Brasil, foi possível o cálculo do IQE e a seleção dos indicadores. As atividades com número de casos suficiente nas amostras das PNADs, em toda a série e com a devida individualização na Classificação Nacional das Atividades Econômicas (CNAE), selecionadas para análise são: arroz, café, cana-de-açúcar, mandioca, milho e soja (Tabela 2).

Vale lembrar, no entanto, que os indicadores utilizados no presente texto foram calculados para os totais de empregados permanentes e temporários, nas culturas selecionadas, nas grandes regiões e no total de Brasil. Esses totais foram obtidos pela expansão das amostras, multiplicando-se o peso de cada pessoa entrevistada na pesquisa pelos respectivos números de casos apresentados nas Tabelas 1 e 2 .

Finalmente, é preciso salientar que a área rural da região Norte não foi considerada na análise porque somente a partir de 2004 a PNAD passou a considerá-la em suas amostragens. Portanto, para manter a comparabilidade da série histórica, tal região não foi incluída.

Tabela 2

Número de casos nas amostras da PNAD para empregado permanente e temporário, segundo a área e a cultura Brasil, 1992-2004

\begin{tabular}{|c|c|c|c|c|c|c|c|c|c|c|}
\hline \multirow{3}{*}{ Culturas } & \multicolumn{10}{|c|}{ Empregado Permanente } \\
\hline & \multicolumn{5}{|c|}{ Urbano } & \multicolumn{5}{|c|}{ Rural } \\
\hline & 1992 & 1995 & 1998 & 2001 & 2004 & 1992 & 1995 & 1998 & 2001 & 2004 \\
\hline Arroz & 49 & 54 & 30 & 18 & 34 & 88 & 61 & 42 & 46 & 43 \\
\hline Café & 104 & 93 & 78 & 105 & 105 & 294 & 269 & 319 & 338 & 234 \\
\hline Cana-de-açúcar & 297 & 309 & 254 & 193 & 237 & 388 & 366 & 298 & 198 & 221 \\
\hline Mandioca & 30 & 23 & 11 & 24 & 39 & 64 & 35 & 34 & 34 & 51 \\
\hline Milho & 87 & 105 & 58 & 49 & 37 & 234 & 163 & 133 & 80 & 69 \\
\hline Soja & 92 & 46 & 58 & 62 & 103 & 130 & 105 & 98 & 81 & 171 \\
\hline \multirow{3}{*}{ Culturas } & \multicolumn{10}{|c|}{ Empregado Temporário } \\
\hline & \multicolumn{5}{|c|}{ Urbano } & \multicolumn{5}{|c|}{ Rural } \\
\hline & 1992 & 1995 & 1998 & 2001 & 2004 & 1992 & 1995 & 1998 & 2001 & 2004 \\
\hline Arroz & 109 & 51 & 76 & 36 & 72 & 116 & 46 & 53 & 20 & 66 \\
\hline Café & 190 & 138 & 237 & 195 & 257 & 141 & 145 & 194 & 208 & 208 \\
\hline Cana-de-açúcar & 330 & 273 & 131 & 208 & 270 & 225 & 153 & 102 & 151 & 158 \\
\hline Mandioca & 120 & 75 & 76 & 80 & 143 & 211 & 223 & 193 & 180 & 234 \\
\hline Milho & 183 & 128 & 121 & 145 & 127 & 357 & 266 & 285 & 248 & 272 \\
\hline Soja & 46 & 27 & 33 & 41 & 69 & 36 & 24 & 30 & 24 & 36 \\
\hline
\end{tabular}

Fonte: Elaboração dos autores a partir dos microdados da PNAD. 


\subsection{A polarização no grau de formalidade}

Os dados das Tabelas 3A e 3B mostram que, para o total de Brasil, todas as categorias tiveram taxas de crescimento positivas na participação dos empregados com carteira, sendo o período 2001-2004 o mais favorável para a expansão do trabalho formal. Esse movimento está de acordo com os resultados obtidos por Dedecca e Rosandiski (2006), quando analisaram a recomposição do mercado de trabalho formal após a desvalorização cambial do início de 1999.

No entanto, ainda prevaleciam condições muito mais favoráveis para os empregados permanentes: em 2004, 50,0\% e 49,6\%, respectivamente, dos permanentes com residência urbana e rural tinham registro em carteira, contra apenas $14,2 \%$ dos temporários urbanos e 4,8\% dos temporários rurais. É possível perceber que esse quadro se repetiu para as cinco regiões, com apenas uma exceção: os empregados temporários com residência urbana da região Sudeste, que apresentaram uma participação de 44,0\% de carteira assinada, em 2004. Esse valor foi três vezes maior que a média nacional da categoria $(14,2 \%)$ e muito superior às médias verificadas para os empregados temporários nas demais situações.

Tabela 3A

Evolução do indicador de empregados com carteira assinada (Cart), em porcentagem Brasil, Grandes Regiões e Culturas Selecionadas, 1992-2004

Empregado Permanente

\begin{tabular}{|c|c|c|c|c|c|c|c|c|c|c|c|c|c|c|}
\hline \multirow[b]{2}{*}{$\begin{array}{c}\text { Brasil, Regiões e } \\
\text { Culturas }\end{array}$} & \multicolumn{5}{|c|}{ Urbano } & \multicolumn{2}{|c|}{ Tx. Cresc.(1) } & \multicolumn{5}{|c|}{ Rural } & \multicolumn{2}{|c|}{ Tx. Cresc.(1) } \\
\hline & 1992 & 1995 & 1998 & 2001 & 2004 & $\begin{array}{l}1992- \\
2004\end{array}$ & $\begin{array}{l}2001- \\
2004\end{array}$ & 1992 & 1995 & 1998 & 2001 & 2004 & $\begin{array}{l}1992- \\
2004\end{array}$ & $\begin{array}{l}2001- \\
2004\end{array}$ \\
\hline Brasi & 35,0 & 34,9 & 38,4 & 41,2 & 50,0 & 3,0 & 6,6 & 36,8 & 40,8 & 43,7 & 44,9 & 49,6 & 2,5 & 3,4 \\
\hline
\end{tabular}

Grandes Regiões

\begin{tabular}{l|l|l|l|l|l|l|l|l|l|l|l|l|l|l}
\hline Norte Urbano & 7,6 & 10,2 & 13,1 & 20,3 & 35,5 & 13,7 & 20,5 & - & - & - & - & - & - & - \\
\hline
\end{tabular}

\begin{tabular}{|c|c|c|c|c|c|c|c|c|c|c|c|c|c|c|}
\hline Nordeste & 27,5 & 32,3 & 41,1 & 36,6 & 43,0 & 3,8 & 5,5 & 22,2 & 26,4 & 28,0 & 29,1 & 33,4 & 3,5 & 4,7 \\
\hline
\end{tabular}

\begin{tabular}{|l|l|l|l|l|l|l|l|l|l|l|l|l|l|r}
\hline Centro-Oeste & 26,0 & 27,1 & 31,8 & 38,9 & 49,2 & 5,5 & 8,2 & 34,5 & 36,2 & 43,5 & 48,6 & 56,8 & 4,3 & 5,4 \\
\hline
\end{tabular}

\begin{tabular}{l|l|l|l|l|l|l|l|l|l|l|l|l|l|l|}
\hline Sudeste & 55,0 & 54,1 & 54,1 & 62,8 & 66,5 & 1,6 & 2,0 & 38,9 & 45,4 & 44,8 & 51,0 & 52,0 & 2,5 & 0,6 \\
\hline
\end{tabular}

\begin{tabular}{l|l|l|l|l|l|l|l|l|l|l|l|l|l|l}
\hline Sul & 58,7 & 51,0 & 52,0 & 47,5 & 55,5 & $-0,5$ & 5,4 & 51,6 & 55,1 & 58,6 & 50,9 & 56,0 & 0,7 & 3,2 \\
\hline
\end{tabular}

Culturas

\begin{tabular}{l|l|l|l|l|l|l|l|l|l|l|l|l|l|l}
\hline Arroz & 38,0 & 42,7 & 41,4 & 44,5 & 45,9 & 1,6 & 1,1 & 39,2 & 43,9 & 70,3 & 34,3 & 57,1 & 3,2 & 18,5 \\
\hline
\end{tabular}

\begin{tabular}{l|l|l|l|l|l|l|l|l|l|l|l|l|l|l|}
\hline Café & 29,0 & 43,1 & 44,3 & 54,3 & 63,2 & 6,7 & 5,2 & 27,0 & 30,8 & 37,8 & 43,5 & 46,0 & 4,5 & 1,9 \\
\hline
\end{tabular}

\begin{tabular}{l|l|l|l|l|l|l|l|l|l|l|l|l|l|l}
\hline Cana-de-açúcar & 75,3 & 78,5 & 82,6 & 90,5 & 93,0 & 1,8 & 0,9 & 60,3 & 66,0 & 64,6 & 65,4 & 64,9 & 0,6 & $-0,3$ \\
\hline
\end{tabular}

\begin{tabular}{|l|r|r|r|r|r|r|l|r|r|r|r|r|r|r|}
\hline Mandioca & 8,9 & 11,6 & 15,8 & 0,0 & 2,1 & $-11,5$ & - & 3,8 & 0,0 & 15,1 & 21,8 & 8,7 & 7,3 & $-26,4$ \\
\hline
\end{tabular}

\begin{tabular}{l|r|r|r|r|r|r|r|r|r|r|r|r|r|r}
\hline Milho & 16,1 & 11,8 & 20,8 & 31,3 & 30,5 & 5,5 & $-0,8$ & 11,4 & 13,7 & 20,5 & 24,5 & 20,7 & 5,1 & $-5,4$ \\
\hline
\end{tabular}

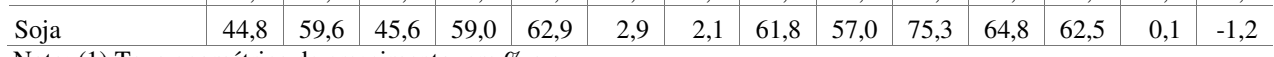

Nota: (1) Taxa geométrica de crescimento, em \% a.a.

Fonte: Elaboração dos autores a partir dos microdados da PNAD. 
Otávio Valentim Balsadi / José Francisco Graziano da Silva

Tabela 3B

Evolução do indicador de empregados com carteira assinada (Cart), em porcentagem Brasil, Grandes Regiões e Culturas Selecionadas, 1992-2004

Empregado Temporário

\begin{tabular}{|c|c|c|c|c|c|c|c|c|c|c|c|c|c|c|}
\hline \multirow{2}{*}{$\begin{array}{c}\text { Brasil, Regiões e } \\
\text { Culturas }\end{array}$} & \multicolumn{5}{|c|}{ Urbano } & \multicolumn{2}{|c|}{$\begin{array}{c}\text { Tx. } \\
\text { Cresc.(1) }\end{array}$} & \multicolumn{5}{|c|}{ Rural } & \multicolumn{2}{|c|}{ Tx. Cresc.(1) } \\
\hline & 1992 & 1995 & 1998 & 2001 & 2004 & $\begin{array}{c}1992- \\
2004\end{array}$ & $\begin{array}{c}2001- \\
2004\end{array}$ & 1992 & 1995 & 1998 & 2001 & 2004 & $\begin{array}{l}1992- \\
2004\end{array}$ & $\begin{array}{l}2001- \\
2004\end{array}$ \\
\hline Brasil & 10,6 & 11,5 & 8,0 & 11,1 & 14,2 & 2,5 & 8,8 & 2,7 & 5,0 & 4,1 & 2,9 & 4,8 & 5,0 & 19,0 \\
\hline \multicolumn{15}{|l|}{ Grandes Regiões } \\
\hline Norte Urbano & 0,0 & 1,5 & 0,6 & 0,8 & 3,9 & - & 73,2 & - & - & - & - & - & - & - \\
\hline Nordeste & 8,5 & 4,6 & 4,2 & 5,6 & 9,7 & 1,1 & 20,4 & 3,1 & 3,3 & 2,9 & 2,6 & 5,7 & 5,3 & 29,6 \\
\hline Centro-Oeste & 5,5 & 2,7 & 1,4 & 13,2 & 10,7 & 5,7 & $-6,7$ & 0,8 & 0,7 & 0,0 & 1,6 & 0,6 & $-1,9$ & $-27,1$ \\
\hline Sudeste & 20,6 & 24,3 & 16,6 & 29,0 & 44,0 & 6,5 & 14,9 & 2,3 & 5,2 & 6,4 & 4,4 & 9,5 & 12,7 & 29,4 \\
\hline Sul & 7,7 & 24,4 & 17,2 & 6,9 & 2,9 & $-7,7$ & $-24,8$ & 4,8 & 10,9 & 3,0 & 0,0 & 3,5 & $-2,4$ & - \\
\hline \multicolumn{15}{|l|}{ Culturas } \\
\hline Arroz & 0,0 & 4,4 & 1,8 & 5,9 & 1,7 & - & $-33,4$ & 5,1 & 2,5 & 2,1 & 0,0 & 4,8 & $-0,4$ & - \\
\hline Café & 2,6 & 13,6 & 13,3 & 14,3 & 32,6 & 23,6 & 31,5 & 0,7 & 11,5 & 11,1 & 3,8 & 12,7 & 26,7 & 49,2 \\
\hline Cana-de-açúcar & 47,9 & 59,2 & 57,1 & 63,8 & 66,8 & 2,8 & 1,6 & 19,3 & 31,3 & 34,9 & 26,8 & 39,7 & 6,2 & 14,0 \\
\hline Mandioca & 0,0 & 0,0 & 0,0 & 0,0 & 0,0 & - & - & 0,0 & 0,0 & 0,5 & 0,0 & 0,0 & - & - \\
\hline Milho & 0,0 & 3,1 & 0,0 & 3,4 & 5,9 & - & 20,3 & 0,3 & 0,0 & 0,0 & 0,9 & 0,4 & 3,1 & $-21,9$ \\
\hline Soja & 5,2 & 5,5 & 0,0 & 7,7 & 13,0 & 7,9 & 19,1 & 0,0 & 0,0 & 0,0 & 0,0 & 0,0 & - & - \\
\hline
\end{tabular}

Nota: (1) Taxa geométrica de crescimento, em \% a.a.

Fonte: Elaboração dos autores a partir dos microdados da PNAD.

Como pode ser visto pelos dados para as culturas selecionadas, o crescimento do grau de formalidade dos empregados temporários do Sudeste, principalmente dos residentes urbanos, foi determinado pelo desempenho das culturas do café e da cana-de-açúcar, nas quais já existe um mercado de trabalho assalariado mais estruturado e um movimento sindical com maior histórico e tradição de lutas por melhores condições de trabalho. Em 2004, 66,8\% e 32,6\%, respectivamente, dos empregados temporários urbanos ocupados nas culturas da cana-de-açúcar e do café tinham carteira assinada. Pode-se notar que os temporários rurais ocupados nessas culturas também possuíam níveis de formalidade $(39,7 \%$ e $12,7 \%$, respectivamente) bem maiores do que aqueles registrados para as médias regionais e das demais culturas selecionadas.

Se, nas regiões, o quadro de melhores condições para os empregados permanentes se repetiu, o mesmo ocorreu nas culturas selecionadas. Com exceção das culturas do café e da cana, era abissal a diferença do grau de formalidade dos empregados temporários das demais culturas em relação aos permanentes.

Tal situação permite detalhar as discrepâncias entre as regiões, entre as culturas e mesmo entre as mesmas categorias de empregados. Em que pese o fato de todas as regiões terem apresentado taxas de crescimento positivas na participação dos empregados com carteira assinada (as exceções foram o Sul, nas categorias de empregados permanentes urbanos e de temporários, urbanos e rurais, e o CentroOeste, na categoria de temporários rurais), os maiores índices de formalidade 
estavam no Centro-Sul, principalmente para os empregados permanentes, cujas médias de participação ficaram acima da média nacional.

Entre as culturas, com raras exceções, os maiores níveis de formalidade do emprego foram registrados para a cana-de-açúcar, o café e a soja. Já os menores ficaram com a mandioca, o milho e o arroz. É possível perceber que, nas culturas da cana e do café, a participação dos empregados temporários com registro em carteira foi maior que a participação dos empregados permanentes formais ocupados nas culturas da mandioca e do milho.

Com isso, pode-se afirmar que, mesmo entre os temporários, aqueles que estavam ocupados na cana e no café estavam em situação melhor do que aqueles ocupados nas demais culturas. O mesmo raciocínio também vale para os permanentes, ou seja: nessa categoria, os indicadores para aqueles ocupados nas principais commodities eram bem melhores do que os verificados para as culturas alimentares de mercado doméstico.

Em linhas gerais, os dados das Tabelas 4A e 4B, referentes à participação dos empregados na agricultura brasileira com contribuição para a Previdência Social, mostram um quadro muito semelhante ao apresentado para o indicador de carteira assinada e, assim, não será repetida sua análise. Isso porque a formalidade do trabalho é uma das importantes condições para a obtenção das aposentadorias pelos empregados.

Tabela 4A

Evolução do indicador de contribuição para a Previdência Social (Prev), em porcentagem Brasil, Grandes Regiões e Culturas Selecionadas, 1992-2004 Empregado Permanente

\begin{tabular}{|c|c|c|c|c|c|c|c|c|c|c|c|c|c|c|}
\hline \multirow{2}{*}{$\begin{array}{c}\text { Brasil, Regiões e } \\
\text { Culturas }\end{array}$} & \multicolumn{5}{|c|}{ Urbano } & \multicolumn{2}{|c|}{ Tx. Cresc.(1) } & \multicolumn{5}{|c|}{ Rural } & \multicolumn{2}{|c|}{$\begin{array}{c}\text { Tx. } \\
\text { Cresc.(1) }\end{array}$} \\
\hline & 1992 & 1995 & 1998 & 2001 & 2004 & $\begin{array}{l}1992- \\
2004\end{array}$ & $\begin{array}{c}2001- \\
2004\end{array}$ & 1992 & 1995 & 1998 & 2001 & 2004 & $\begin{array}{l}1992- \\
2004\end{array}$ & $\begin{array}{l}2001- \\
2004\end{array}$ \\
\hline Brasil & 32,1 & 33,9 & 39,5 & 41,7 & 50,6 & 3,9 & 6,6 & 34,5 & 39,3 & 44,3 & 46,1 & 50,4 & 3,2 & 3,0 \\
\hline
\end{tabular}

Grandes Regiões

\begin{tabular}{l|r|r|r|r|r|r|r|r|r|r|r|r|r|r}
\hline Norte Urbano & 7,6 & 9,0 & 14,6 & 20,7 & 35,5 & 13,7 & 19,6 & - & - & - & - & - & - & - \\
\hline Nordeste & 23,7 & 30,6 & 41,8 & 37,4 & 43,5 & 5,2 & 5,1 & 17,7 & 25,1 & 28,4 & 29,3 & 33,8 & 5,5 & 4,8 \\
\hline Centro-Oeste & 24,2 & 24,7 & 32,5 & 39,5 & 49,9 & 6,2 & 8,1 & 32,9 & 35,2 & 43,6 & 49,3 & 57,6 & 4,8 & 5,3 \\
\hline Sudeste & 51,8 & 55,2 & 55,5 & 63,5 & 67,7 & 2,2 & 2,2 & 38,5 & 45,7 & 46,4 & 52,7 & 53,0 & 2,7 & 0,2 \\
\hline Sul & 53,3 & 49,9 & 53,3 & 47,5 & 56,4 & 0,5 & 5,9 & 49,1 & 51,2 & 58,9 & 53,2 & 57,0 & 1,3 & 2,4 \\
\hline Culturas & 40,5 & 42,7 & 41,4 & 44,5 & 45,9 & 1,0 & 1,1 & 39,1 & 40,3 & 70,3 & 34,3 & 59,9 & 3,6 & 20,4 \\
\hline Arroz & 26,2 & 42,5 & 46,2 & 54,3 & 63,2 & 7,6 & 5,2 & 25,3 & 31,0 & 38,1 & 45,8 & 46,9 & 5,3 & 0,8 \\
\hline Café & 65,0 & 76,2 & 84,0 & 91,4 & 93,4 & 3,1 & 0,7 & 48,9 & 65,2 & 65,4 & 66,0 & 65,3 & 2,4 & $-0,3$ \\
\hline Cana-de-açúcar & 8,9 & 11,6 & 15,8 & 0,0 & 2,1 & $-11,5$ & - & 3,8 & 0,0 & 15,1 & 21,8 & 8,7 & 7,3 & $-26,4$ \\
\hline Mandioca & 14,9 & 13,9 & 20,8 & 32,5 & 33,1 & 6,9 & 0,7 & 12,3 & 13,5 & 20,5 & 24,5 & 23,0 & 5,3 & $-2,1$ \\
\hline Milho & 44,1 & 56,6 & 49,9 & 59,0 & 62,9 & 3,0 & 2,1 & 60,7 & 55,2 & 75,3 & 64,8 & 62,9 & 0,3 & $-1,0$ \\
\hline Soja
\end{tabular}

Nota: (1) Taxa geométrica de crescimento, em \% a.a.

Fonte: Elaboração dos autores a partir dos microdados da PNAD. 
A polarização da qualidade do emprego na agricultura brasileira no período 1992-2004

Para as regiões e culturas selecionadas, a situação foi bastante semelhante, mas algumas diferenciações importantes devem ser pontuadas, como é o caso dos temporários, rurais e urbanos, no Centro-Oeste, dos temporários urbanos no Sudeste e dos temporários urbanos ocupados nas culturas da cana, da soja e, em menor proporção, do café.

Quanto às regiões, três resultados chamam a atenção: a) os melhores indicadores para os empregados permanentes em todas elas; b) a situação muito desfavorável da região Nordeste, cujos indicadores para todas as categorias estão sistematicamente bem abaixo das médias nacionais; c) a situação muito discrepante dos empregados temporários rurais de duas regiões desenvolvidas, o Sudeste e o Sul, cujos indicadores ficaram abaixo do Centro-Oeste.

Aliás, em termos regionais, o Centro-Oeste e o Nordeste são os extremos em relação ao indicador de participação dos empregados que recebiam mais de um salário mínimo por mês. Em 2004, enquanto 82,4\% dos empregados permanentes com residência urbana no Centro-Oeste tinham rendimentos acima do salário mínimo, no Nordeste, o valor foi de 31,9\%. Para os empregados permanentes com residência rural, os valores respectivos foram de $82,4 \%$ e $23,1 \%$. Já para os empregados temporários, os valores foram de $58,7 \%$ e $11,5 \%$ e de $51,6 \%$ e $6,5 \%$, respectivamente, para os residentes urbanos e rurais das duas regiões.

Novamente, vale destacar que o comportamento favorável para os empregados temporários com residência urbana no Sudeste foi muito influenciado pelos resultados obtidos pelas culturas da cana e do café, para as quais a região é a principal produtora nacional (em 2004, 53,3\% e 34,2\%, respectivamente, dos temporários recebiam mais de um salário mínimo mensal). Da mesma forma, o comportamento diferenciado dos temporários rurais e urbanos do Centro-Oeste foi influenciado pelos indicadores da cultura da soja, principal atividade da região (em 2004, 41,7\% e 65,2\%, respectivamente, dos empregados temporários tinham rendimento médio mensal acima do mínimo vigente).

Entre as culturas selecionadas, a mandioca e o milho foram as que apresentaram os piores indicadores, particularmente para os empregados residentes nas áreas rurais (tanto os permanentes quanto os temporários). Em 2004, somente $3,4 \%$ e $3,7 \%$, respectivamente, dos empregados temporários rurais ocupados nessas culturas receberam mais de um salário mínimo por mês. Para os permanentes rurais, os valores foram de $11,8 \%$ e $26,1 \%$, respectivamente. Também para os residentes urbanos, os valores estiveram muito aquém dos verificados para as médias nacional, regional e das demais culturas. O extremo na polarização da qualidade do emprego, vista por esse indicador, foi a cultura da soja, cujos valores foram de $41,7 \%$ para os temporários rurais, 65,2\% para os temporários urbanos, 86,0\% para os permanentes rurais e $91,3 \%$ para os permanentes urbanos. 
Obviamente, o comportamento verificado para o indicador acima tem influência no outro indicador de rendimento no trabalho principal selecionado, que é o rendimento médio mensal. ${ }^{6}$ Pelos dados das Tabelas $6 \mathrm{~A}$ e $6 \mathrm{~B}$, pode-se observar que, para o total de Brasil, os temporários rurais recebiam, em 2004, 69,7\%, 54,1\% e $45,7 \%$ do que recebiam, respectivamente, os temporários urbanos, os permanentes rurais e os permanentes urbanos.

Esse comportamento também foi o padrão dominante nas regiões e nas culturas selecionadas. Como exceções, podem ser citados os casos dos empregados temporários urbanos ocupados nas culturas da cana e da mandioca, que tiveram um rendimento médio mensal maior que os empregados permanentes rurais nas mesmas atividades.

Os dados regionais evidenciam que a região Centro-Oeste teve, em 2004 (mas também em quase toda a série analisada), os maiores rendimentos médios mensais para todas as categorias de empregados, ao passo que o Nordeste apresentou os menores rendimentos para todas as categorias de empregados na agricultura brasileira.

Tabela 5A

Evolução do indicador de empregados que recebiam mais de um salário mínimo por mês (Npob), em Porcentagem Brasil, Grandes Regiões e Culturas Selecionadas, 1992-2004 Empregado Permanente

\begin{tabular}{|c|c|c|c|c|c|c|c|c|c|c|c|c|c|c|}
\hline \multirow{2}{*}{$\begin{array}{c}\text { Brasil, Regiões e } \\
\text { Culturas }\end{array}$} & \multicolumn{5}{|c|}{ Urbano } & \multicolumn{2}{|c|}{$\begin{array}{c}\text { Tx. } \\
\text { Cresc.(1) }\end{array}$} & \multicolumn{5}{|c|}{ Rural } & \multicolumn{2}{|c|}{ Tx. Cresc.(1) } \\
\hline & 1992 & 1995 & 1998 & 2001 & 2004 & $\begin{array}{l}1992- \\
2004\end{array}$ & $\begin{array}{c}2001- \\
2004\end{array}$ & 1992 & 1995 & 1998 & 2001 & 2004 & $\begin{array}{c}1992- \\
2004\end{array}$ & $\begin{array}{c}2001- \\
2004\end{array}$ \\
\hline Brasil & 46,8 & 61,5 & 66,0 & 60,0 & 62,4 & 2,4 & 1,3 & 40,2 & 55,8 & 59,0 & 57,2 & 56,1 & 2,8 & $-0,6$ \\
\hline \multicolumn{15}{|l|}{ Grandes Regiões } \\
\hline Norte Urbano & 37,3 & 61,8 & 61,8 & 55,4 & 59,4 & 3,9 & 2,3 & - & - & - & - & - & - & - \\
\hline Nordeste & 24,2 & 36,7 & 40,1 & 32,0 & 31,9 & 2,3 & $-0,1$ & 17,6 & 32,7 & 31,2 & 27,2 & 23,1 & 2,3 & $-5,3$ \\
\hline Centro-Oeste & 56,9 & 73,9 & 79,3 & 77,5 & 82,4 & 3,1 & 2,0 & 52,4 & 67,7 & 78,8 & 81,6 & 82,4 & 3,8 & 0,3 \\
\hline Sudeste & 52,1 & 65,9 & 71,2 & 67,4 & 67,4 & 2,2 & 0,0 & 36,5 & 58,3 & 58,8 & 54,4 & 49,4 & 2,5 & $-3,2$ \\
\hline Sul & 63,4 & 69,3 & 77,3 & 67,7 & 70,9 & 0,9 & 1,5 & 54,1 & 64,5 & 67,2 & 65,7 & 69,6 & 2,1 & 2,0 \\
\hline \multicolumn{15}{|l|}{ Culturas } \\
\hline Arroz & 61,2 & 77,8 & 86,7 & 72,2 & 70,6 & 1,2 & $-0,8$ & 56,8 & 60,7 & 71,4 & 60,9 & 86,1 & 3,5 & 12,2 \\
\hline Café & 25,0 & 57,0 & 69,2 & 50,5 & 53,3 & 6,5 & 1,8 & 32,7 & 56,1 & 55,8 & 46,5 & 43,2 & 2,4 & $-2,4$ \\
\hline Cana-de-açúcar & 57,6 & 72,2 & 74,0 & 73,1 & 69,6 & 1,6 & $-1,6$ & 41,8 & 56,6 & 49,3 & 43,4 & 41,6 & 0,0 & $-1,4$ \\
\hline Mandioca & 20,0 & 26,1 & 45,5 & 45,8 & 25,6 & 2,1 & $-17,6$ & 10,9 & 17,1 & 17,7 & 20,6 & 11,8 & 0,6 & $-17,0$ \\
\hline Milho & 25,3 & 54,3 & 43,1 & 42,9 & 43,2 & 4,6 & 0,3 & 20,9 & 36,8 & 36,1 & 30,0 & 26,1 & 1,8 & $-4,5$ \\
\hline Soja & 70,7 & 87,0 & 86,2 & 72,6 & 91,3 & 2,2 & 7,9 & 69,2 & 81,9 & 87,8 & 88,9 & 86,0 & 1,8 & $-1,1$ \\
\hline
\end{tabular}

Nota: (1) Taxa geométrica de crescimento, em \% a.a.

Fonte: Elaboração dos autores a partir dos microdados da PNAD.

(6) Pelas controvérsias que sempre aparecem na questão do rendimento dos trabalhadores no período 1992-1995, em função da correção da inflação no período imediatamente anterior à conversão da URV no Real, e de como os índices de preços captaram isto, optou-se por montar a série com o indicador de rendimento médio mensal somente com o período 1995-2004, para o qual o problema levantado não ocorre. 
A polarização da qualidade do emprego na agricultura brasileira no período 1992-2004

Tabela 5B

Evolução do indicador de empregados que recebiam mais de um salário mínimo por mês (Npob), em Porcentagem Brasil, Grandes Regiões e Culturas Selecionadas, 1992-2004

Empregado Temporário

\begin{tabular}{|c|c|c|c|c|c|c|c|c|c|c|c|c|c|c|}
\hline \multirow{2}{*}{$\begin{array}{l}\text { Brasil, Regiões e } \\
\text { Culturas }\end{array}$} & \multicolumn{5}{|c|}{ Urbano } & \multicolumn{2}{|c|}{$\begin{array}{c}\text { Tx. } \\
\text { Cresc.(1) }\end{array}$} & \multicolumn{5}{|c|}{ Rural } & \multicolumn{2}{|c|}{$\begin{array}{c}\text { Tx. } \\
\text { Cresc.(1) }\end{array}$} \\
\hline & 1992 & 1995 & 1998 & 2001 & 2004 & $\begin{array}{l}1992- \\
2004\end{array}$ & $\begin{array}{l}2001- \\
2004\end{array}$ & 1992 & 1995 & 1998 & 2001 & 2004 & $\begin{array}{l}1992- \\
2004\end{array}$ & $\begin{array}{l}2001- \\
2004\end{array}$ \\
\hline Brasil & 26,3 & 48,7 & 45,6 & 38,6 & 38,2 & 3,2 & $-0,3$ & 15,9 & 35,8 & 32,2 & 24,2 & 27,7 & 4,7 & 4,5 \\
\hline \multicolumn{15}{|l|}{ Grandes Regiões } \\
\hline Norte Urbano & 32,4 & 51,9 & 39,2 & 44,7 & 37,7 & 1,3 & $-5,6$ & - & - & - & - & - & - & - \\
\hline Nordeste & 14,6 & 24,8 & 11,6 & 10,1 & 11,5 & $-1,9$ & 4,5 & 7,7 & 14,6 & 10,0 & 4,9 & 6,5 & $-1,4$ & 9,8 \\
\hline Centro-Oeste & 36,8 & 56,5 & 63,1 & 58,3 & 58,7 & 4,0 & 0,2 & 23,5 & 56,4 & 47,2 & 45,2 & 51,6 & 6,8 & 4,5 \\
\hline Sudeste & 29,1 & 63,4 & 65,2 & 46,1 & 51,2 & 4,8 & 3,6 & 11,6 & 32,8 & 34,0 & 18,6 & 21,8 & 5,4 & 5,4 \\
\hline Sul & 18,7 & 46,7 & 49,0 & 34,0 & 32,1 & 4,6 & $-1,8$ & 20,8 & 39,6 & 37,6 & 28,1 & 30,7 & 3,3 & 3,0 \\
\hline \multicolumn{15}{|l|}{ Culturas } \\
\hline Arroz & 21,1 & 41,2 & 36,8 & 16,7 & 27,8 & 2,3 & 18,6 & 12,9 & 32,6 & 30,2 & 15,0 & 15,2 & 1,3 & 0,3 \\
\hline Café & 12,1 & 54,4 & 62,5 & 29,7 & 34,2 & 9,0 & 4,8 & 6,4 & 42,1 & 39,7 & 12,5 & 22,6 & 11,1 & 21,8 \\
\hline Cana-de-açúcar & 44,9 & 60,1 & 56,5 & 56,3 & 53,3 & 1,5 & $-1,8$ & 26,7 & 34,6 & 44,1 & 23,2 & 26,0 & $-0,2$ & 3,8 \\
\hline Mandioca & 7,5 & 33,3 & 25,0 & 13,8 & 16,8 & 6,9 & 6,9 & 2,8 & 9,4 & 10,4 & 3,9 & 3,4 & 1,6 & $-4,2$ \\
\hline Milho & 12,0 & 41,4 & 34,7 & 18,6 & 27,6 & 7,2 & 14,0 & 5,9 & 21,8 & 20,0 & 8,9 & 3,7 & $-3,8$ & $-25,4$ \\
\hline Soja & 34,8 & 59,3 & 63,6 & 37,5 & 65,2 & 5,4 & 20,3 & 41,7 & 45,8 & 43,3 & 37,5 & 41,7 & 0,0 & 3,6 \\
\hline
\end{tabular}

Nota: (1) Taxa geométrica de crescimento, em \% a.a.

Fonte: Elaboração dos autores a partir dos microdados da PNAD.

Tabela 6A

Evolução do indicador de Rendimento Médio Mensal dos Empregados (Rend), em reais de dezembro de 2005

Brasil, Grandes Regiões e Culturas Selecionadas, 1995-2004 Empregado Permanente

\begin{tabular}{|c|c|c|c|c|c|c|c|c|c|c|c|c|}
\hline \multirow{2}{*}{$\begin{array}{c}\text { Brasil, Regiões e } \\
\text { Culturas }\end{array}$} & \multicolumn{4}{|c|}{ Urbano } & \multicolumn{2}{|c|}{$\begin{array}{c}\text { Tx. } \\
\text { Cresc.(1) }\end{array}$} & \multicolumn{4}{|c|}{ Rural } & \multicolumn{2}{|c|}{$\begin{array}{c}\text { Tx. } \\
\text { Cresc.(1) }\end{array}$} \\
\hline & 1995 & 1998 & 2001 & 2004 & $\begin{array}{l}1995- \\
2004\end{array}$ & $\begin{array}{l}2001- \\
2004\end{array}$ & 1995 & 1998 & 2001 & 2004 & $\begin{array}{l}1995- \\
2004\end{array}$ & $\begin{array}{l}2001- \\
2004\end{array}$ \\
\hline Brasil & 378,19 & 397,01 & 406,06 & 432,09 & 1,1 & 2,1 & 318,11 & 348,34 & 348,47 & 364,53 & 1,1 & 1,5 \\
\hline \multicolumn{13}{|l|}{ Grandes Regiões } \\
\hline Norte Urbano & 385,31 & 406,26 & 374,66 & 436,86 & 1,1 & 5,3 & - & - & - & - & - & - \\
\hline Nordeste & 237,63 & 299,53 & 285,28 & 321,33 & 2,5 & 4,0 & 225,33 & 225,26 & 248,17 & 260,70 & 1,2 & 1,7 \\
\hline Centro-Oeste & 471,16 & 508,33 & 566,93 & 574,32 & 1,7 & 0,4 & 392,28 & 472,57 & 523,68 & 543,24 & 2,8 & 1,2 \\
\hline Sudeste & 427,61 & 400,07 & 435,26 & 430,07 & 0,0 & $-0,4$ & 359,22 & 378,95 & 367,70 & 359,62 & 0,0 & $-0,7$ \\
\hline Sul & 455,80 & 427,67 & 375,25 & 533,22 & 1,3 & 12,4 & 358,45 & 395,24 & 375,23 & 430,55 & 1,5 & 4,7 \\
\hline \multicolumn{13}{|l|}{ Culturas } \\
\hline Arroz & 458,84 & 505,92 & 436,82 & 414,85 & $-0,8$ & $-1,7$ & 316,42 & 359,66 & 409,10 & 656,56 & 6,3 & 17,1 \\
\hline Café & 348,74 & 337,09 & 362,08 & 340,41 & $-0,2$ & $-2,0$ & 323,82 & 344,24 & 318,99 & 316,50 & $-0,2$ & $-0,3$ \\
\hline Cana-de-açúcar & 413,54 & 445,15 & 438,30 & 458,64 & 0,9 & 1,5 & 394,42 & 372,88 & 296,88 & 334,93 & $-1,4$ & 4,1 \\
\hline Mandioca & 219,77 & 306,80 & 229,64 & 236,04 & 0,6 & 0,9 & 173,09 & 189,20 & 241,03 & 213,34 & 1,8 & $-4,0$ \\
\hline Milho & 353,53 & 273,86 & 282,06 & 358,83 & 0,1 & 8,4 & 223,00 & 252,01 & 268,27 & 257,57 & 1,2 & $-1,3$ \\
\hline Soja & 517,27 & 446,23 & 525,23 & 745,79 & 3,1 & 12,4 & 469,15 & 710,48 & 570,29 & 590,16 & 1,9 & 1,1 \\
\hline
\end{tabular}


Otávio Valentim Balsadi / José Francisco Graziano da Silva

Tabela 6B

Evolução do indicador de Rendimento Médio Mensal dos Empregados (Rend), em reais de dezembro de 2005

Brasil, Grandes Regiões e Culturas Selecionadas, 1995-2004 Empregado Temporário

\begin{tabular}{|c|c|c|c|c|c|c|c|c|c|c|c|c|}
\hline \multirow{2}{*}{$\begin{array}{c}\text { Brasil, Regiões e } \\
\text { Culturas }\end{array}$} & \multicolumn{4}{|c|}{ Urbano } & \multicolumn{2}{|c|}{$\begin{array}{c}\text { Tx. } \\
\text { Cresc.(1) }\end{array}$} & \multicolumn{4}{|c|}{ Rural } & \multicolumn{2}{|c|}{$\begin{array}{c}\text { Tx. } \\
\text { Cresc.(1) }\end{array}$} \\
\hline & 1995 & 1998 & 2001 & 2004 & $\begin{array}{c}1995- \\
2004\end{array}$ & $\begin{array}{c}2001- \\
2004\end{array}$ & 1995 & 1998 & 2001 & 2004 & $\begin{array}{l}1995- \\
2004\end{array}$ & $\begin{array}{l}2001- \\
2004\end{array}$ \\
\hline Brasil & 281,41 & 271,31 & 252,71 & 283,08 & 0,0 & 3,9 & 196,33 & 195,32 & 174,99 & 197,25 & 0,0 & 4,1 \\
\hline
\end{tabular}

Grandes Regiões

\begin{tabular}{l|c|c|c|c|c|c|c|c|c|c|c|c}
\hline Norte Urbano & 322,05 & 270,25 & 295,48 & 297,43 & $-0,7$ & 0,2 & - & - & - & - & - & - \\
\hline Nordeste & 204,82 & 171,93 & 173,76 & 187,87 & $-0,7$ & 2,6 & 166,61 & 161,64 & 149,09 & 168,90 & 0,1 & 4,2 \\
\hline Centro-Oeste & 304,96 & 326,03 & 333,39 & 352,93 & 1,2 & 1,9 & 298,22 & 278,07 & 271,23 & 313,65 & 0,4 & 5,0 \\
\hline Sudeste & 328,57 & 333,94 & 304,25 & 347,67 & 0,5 & 4,5 & 232,14 & 241,50 & 204,96 & 231,53 & 0,0 & 4,1 \\
\hline Sul & 269,58 & 244,15 & 229,15 & 258,53 & $-0,3$ & 4,1 & 224,95 & 218,29 & 211,63 & 247,09 & 0,8 & 5,3 \\
\hline
\end{tabular}

Sul

\begin{tabular}{|l|l|l|l|l|l|l|l|l|l|l|l|}
269,58 & 244,15 & 229,15 & 258,53 & $-0,3$ & 4,1 & 224,95 & 218,29 & 211,63 & 247,09 & 0,8 & 5,3 \\
\hline
\end{tabular}

Culturas

\begin{tabular}{|c|c|c|c|c|c|c|c|c|c|c|c|c|}
\hline Arroz & 242,57 & 228,25 & 162,38 & 199,09 & $-1,6$ & 7,0 & 212,33 & 190,42 & 131,75 & 151,27 & $-2,8$ & 4,7 \\
\hline
\end{tabular}

\begin{tabular}{|c|c|c|c|c|c|c|c|c|c|c|c|c|}
\hline Café & 294,76 & 300,32 & 247,24 & 281,54 & $-0,4$ & 4,4 & 241,35 & 267,10 & 193,87 & 222,80 & $-0,7$ & 4,7 \\
\hline
\end{tabular}

\begin{tabular}{l|l|l|l|l|l|l|l|l|l|l|l|l|}
\hline Cana-de-açúcar & 338,05 & 339,33 & 361,56 & 399,94 & 1,4 & 3,4 & 231,60 & 274,40 & 229,36 & 278,29 & 1,5 & 6,7 \\
\hline
\end{tabular}

\begin{tabular}{l|l|l|l|l|l|l|l|l|l|l|l|l|}
\hline Mandioca & 198,94 & 174,60 & 178,91 & 219,37 & 0,8 & 7,0 & 146,01 & 144,88 & 130,13 & 152,72 & 0,4 & 5,5 \\
\hline
\end{tabular}

\begin{tabular}{l|l|l|l|l|l|l|l|l|l|l|l|l}
\hline Milho & 223,03 & 225,79 & 193,11 & 219,71 & $-0,1$ & 4,4 & 175,46 & 179,35 & 142,81 & 158,86 & $-0,8$ & 3,6 \\
\hline
\end{tabular}

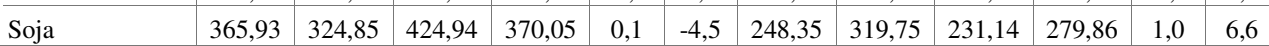

Fonte: Elaboração dos autores a partir dos microdados da PNAD.

Nota: (1) Taxa geométrica de crescimento, em \% a.a.

Para as culturas, os dados de rendimento médio mensal exemplificam bem a situação mais desfavorável dos empregados temporários residentes nas áreas rurais e ocupados nas culturas tradicionais. Em 2004 (mas também em quase toda a série), os três piores rendimentos foram registrados para os empregados temporários rurais ocupados nas culturas do arroz ( $\mathrm{R} \$ 151,27)$, da mandioca ( $\mathrm{R} \$ 152,72)$ e do milho ( $\mathrm{R} \$ 158,86$ ). Do outro lado, os três melhores rendimentos foram observados para os empregados permanentes (urbanos e rurais) ocupados na cultura da soja e para os empregados permanentes rurais ocupados na cultura do arroz, cujo crescimento foi muito expressivo no período 2001-2004.

Apenas como ilustração, as culturas da soja, do arroz e da cana-de-açúcar foram as que proporcionaram os maiores rendimentos médios para os empregados permanentes, tanto para os residentes urbanos quanto para os rurais. Para os temporários (urbanos e rurais), os maiores rendimentos médios foram obtidos nas culturas da cana, da soja e do café.

\subsection{A polarização no nível educacional}

Para o total de Brasil, os dados das Tabelas 7A e 7B mostram o crescimento contínuo da participação dos empregados com oito anos ou mais de estudo. As maiores diferenças neste indicador parecem ser a favor dos empregados permanentes 
com residência urbana, os quais, independentemente do nível de agregação (Brasil, Grandes Regiões e culturas selecionadas) sempre apresentam um nível de participação maior que as demais categorias. Em função da expansão do ensino público, é comum que sejam observadas condições de participação semelhantes entre os permanentes rurais e os temporários urbanos e rurais, o que torna a polarização mais branda neste caso, comparativamente aos indicadores anteriormente analisados.

Em 2004, 13,3\% dos empregados permanentes com residência urbana tinham oito ou mais anos de estudo. Para as demais categorias, os valores foram, praticamente, a metade $(6,6 \%$ para os permanentes rurais, 5,9\% para os temporários urbanos e 5,0\% para os temporários rurais). Nas regiões Norte Urbano, Sudeste e Sul, o quadro foi bem parecido com a situação nacional.

No Nordeste, além do fato de os indicadores estarem bem abaixo das médias nacional e regionais, chama a atenção o fato de a participação dos empregados permanentes urbanos com oito anos ou mais de estudo ser três vezes ou mais superior que as demais categorias. Já na região Centro-Oeste, as participações dos empregados permanentes (rurais e urbanos) foram se aproximando ao longo do período 19922004, e elas continuam bem acima das observadas para os empregados temporários urbanos e rurais.

Tabela 7A

Evolução do Indicador de Empregados com Oito Anos ou mais de Estudo (Indesc2), em porcentagem

Brasil, Grandes Regiões e Culturas Selecionadas, 1992-2004

Empregado Permanente

\begin{tabular}{|c|c|c|c|c|c|c|c|c|c|c|c|c|c|c|}
\hline \multirow{2}{*}{$\begin{array}{c}\text { Brasil, Regiões } \\
\text { e Culturas }\end{array}$} & \multicolumn{5}{|c|}{ Urbano } & \multicolumn{2}{|c|}{$\begin{array}{c}\text { Tx. } \\
\text { Cresc.(1) }\end{array}$} & \multicolumn{5}{|c|}{ Rural } & \multicolumn{2}{|c|}{$\begin{array}{c}\text { Tx. } \\
\text { Cresc.(1) }\end{array}$} \\
\hline & 1992 & 1995 & 1998 & 2001 & 2004 & $\begin{array}{l}1992- \\
2004\end{array}$ & $\begin{array}{c}2001- \\
2004\end{array}$ & 1992 & 1995 & 1998 & 2001 & 2004 & $\begin{array}{c}1992- \\
2004\end{array}$ & $\begin{array}{l}2001- \\
2004\end{array}$ \\
\hline Brasil & 4,1 & 4,8 & 7,1 & 7,7 & 13,3 & 10,4 & 20,0 & 2,0 & 2,5 & 3,0 & 5,1 & 6,6 & 10,7 & 9,2 \\
\hline \multicolumn{15}{|l|}{ Grandes Regiões } \\
\hline Norte Urbano & 3,3 & 3,4 & 9,0 & 6,9 & 13,3 & 12,3 & 24,4 & - & - & - & - & - & - & - \\
\hline Nordeste & 2,5 & 2,3 & 4,1 & 4,3 & 9,8 & 12,2 & 31,8 & 1,1 & 0,6 & 0,9 & 1,7 & 2,9 & 8,2 & 20,1 \\
\hline Centro-Oeste & 4,5 & 3,5 & 6,8 & 8,4 & 10,3 & 7,1 & 6,9 & 2,3 & 2,7 & 3,4 & 6,2 & 9,0 & 12,1 & 13,1 \\
\hline Sudeste & 4,0 & 4,5 & 5,0 & 8,4 & 13,7 & 10,8 & 17,5 & 2,8 & 2,7 & 4,4 & 5,6 & 6,8 & 7,8 & 6,8 \\
\hline Sul & 4,3 & 8,1 & 10,4 & 10,5 & 19,6 & 13,4 & 22,9 & 1,6 & 3,5 & 3,3 & 6,8 & 7,7 & 14,0 & 4,4 \\
\hline \multicolumn{15}{|l|}{ Culturas } \\
\hline Arroz & 4,2 & 3,2 & 8,4 & 2,6 & 5,1 & 1,7 & 26,0 & 1,3 & 3,7 & 0,0 & 2,5 & 4,4 & 11,0 & 21,1 \\
\hline Café & 3,4 & 6,1 & 0,0 & 5,0 & 10,7 & 10,0 & 28,6 & 2,6 & 0,6 & 3,0 & 3,7 & 7,0 & 8,6 & 24,3 \\
\hline Cana-de-Açúcar & 1,5 & 1,2 & 2,5 & 6,6 & 11,3 & 18,3 & 19,8 & 1,9 & 4,4 & 3,3 & 2,8 & 5,5 & 9,4 & 25,8 \\
\hline Mandioca & 0,0 & 2,9 & 15,2 & 0,0 & 14,3 & - & - & 0,0 & 0,0 & 0,0 & 3,7 & 10,1 & - & 39,3 \\
\hline Milho & 1,9 & 2,3 & 0,0 & 9,6 & 6,7 & 11,0 & $-11,5$ & 1,6 & 0,7 & 1,2 & 1,0 & 0,0 & - & - \\
\hline Soja & 1,3 & 13,3 & 15,9 & 5,0 & 15,1 & 22,8 & 44,7 & 4,4 & 2,1 & 9,8 & 8,8 & 15,2 & 10,9 & 19,9 \\
\hline
\end{tabular}

Nota: (1) Taxa geométrica de crescimento, em \% a.a.

Fonte: Elaboração dos autores a partir dos microdados da PNAD. 
Otávio Valentim Balsadi / José Francisco Graziano da Silva

Tabela 7B

Evolução do Indicador de Empregados com Oito Anos ou mais de Estudo (Indesc2), em porcentagem

Brasil, Grandes Regiões e Culturas Selecionadas, 1992-2004 Empregado Temporário

\begin{tabular}{|c|c|c|c|c|c|c|c|c|c|c|c|c|c|c|}
\hline \multirow{2}{*}{$\begin{array}{c}\text { Brasil, Regiões e } \\
\text { Culturas }\end{array}$} & \multicolumn{5}{|c|}{ Urbano } & \multicolumn{2}{|c|}{$\begin{array}{c}\text { Tx. } \\
\text { Cresc.(1) }\end{array}$} & \multicolumn{5}{|c|}{ Rural } & \multicolumn{2}{|c|}{$\begin{array}{c}\text { Tx. } \\
\text { Cresc.(1) }\end{array}$} \\
\hline & 1992 & 1995 & 1998 & 2001 & 2004 & $\begin{array}{l}1992- \\
2004\end{array}$ & \begin{tabular}{c|}
$2001-$ \\
2004
\end{tabular} & 1992 & 1995 & 1998 & 2001 & 2004 & \begin{tabular}{|c|}
$1992-$ \\
2004 \\
\end{tabular} & $\begin{array}{l}2001- \\
2004\end{array}$ \\
\hline Brasil & 1,3 & 2,0 & 2,8 & 3,6 & 5,9 & 13,8 & 18,2 & 1,4 & 1,9 & 2,1 & 3,9 & 5,0 & 11,1 & 8,4 \\
\hline \multicolumn{15}{|l|}{ Grandes Regiões } \\
\hline Norte Urbano & 0,8 & 0,0 & 0,7 & 1,3 & 6,6 & 19,3 & 70,2 & - & - & - & - & - & - & - \\
\hline Nordeste & 0,5 & 1,1 & 0,8 & 1,0 & 3,1 & 17,1 & 47,9 & 0,1 & 0,5 & 1,0 & 1,2 & 2,0 & 29,6 & 20,5 \\
\hline Centro-Oeste & 1,4 & 2,0 & 2,9 & 4,5 & 2,7 & 5,6 & $-15,5$ & 0,9 & 0,7 & 0,7 & 4,8 & 3,8 & 12,3 & $-7,6$ \\
\hline Sudeste & 1,2 & 1,7 & 3,0 & 6,0 & 7,3 & 16,3 & 6,7 & 0,4 & 1,2 & 2,4 & 3,8 & 5,5 & 24,4 & 12,5 \\
\hline Sul & 1,1 & 2,7 & 4,6 & 4,3 & 7,8 & 17,7 & 22,3 & 2,6 & 2,4 & 3,5 & 5,9 & 8,3 & 10,1 & 11,8 \\
\hline \multicolumn{15}{|l|}{ Culturas } \\
\hline Arroz & 0,0 & 1,5 & 0,0 & 0,0 & 4,6 & - & - & 0,0 & 0,0 & 0,0 & 0,0 & 0,0 & - & - \\
\hline Café & 0,0 & 1,4 & 1,3 & 2,1 & 8,6 & - & 60,7 & 0,7 & 0,7 & 1,3 & 3,7 & 6,9 & 21,8 & 23,5 \\
\hline Cana-de-açúcar & 0,2 & 1,3 & 3,6 & 2,9 & 5,4 & 34,0 & 22,9 & 0,3 & 2,0 & 1,9 & 2,0 & 3,6 & 23,2 & 21,2 \\
\hline Mandioca & 0,7 & 3,9 & 2,9 & 4,9 & 7,2 & 22,1 & 14,2 & 0,0 & 1,3 & 2,3 & 1,2 & 1,4 & - & 4,2 \\
\hline Milho & 3,2 & 2,1 & 0,9 & 2,9 & 2,6 & $-1,9$ & $-3,6$ & 0,3 & 0,4 & 0,6 & 3,4 & 2,7 & 19,6 & $-8,1$ \\
\hline Soja & 0,0 & 4,5 & 6,2 & 4,9 & 10,0 & - & 26,9 & 5,7 & 9,4 & 3,9 & 0,0 & 21,9 & 11,9 & - \\
\hline
\end{tabular}

Quanto às culturas selecionadas, é importante dizer que o comportamento do indicador ao longo do período 1992-2004 foi muito oscilante para algumas atividades, talvez em função do número de casos das pessoas sorteadas para a amostragem da PNAD. Mas, o fato concreto é que os dados para 2004 mostram, na grande maioria dos casos, uma situação bem mais favorável em relação àquela observada no início dos anos 1990. Na cultura do arroz, com exceção dos empregados temporários rurais, para os quais não foi captado nenhum trabalhador com a escolaridade igual ou superior aos oito anos, as participações das demais categorias eram muito próximas (ao redor de 5,0\%, em 2004).

O café e a cana tiveram um comportamento semelhante ao que foi relatado para o total de Brasil, com participações relativamente próximas das categorias dos permanentes rurais e dos temporários (urbanos e rurais) e um valor maior para os permanentes urbanos (que foi de cerca de 11,0\%, em 2004).

As culturas da mandioca e da soja foram as que apresentaram os dados mais oscilantes e sem uma tendência muito clara, com alguns valores até mesmo surpreendentes e inesperados quando comparados aos das demais atividades. No entanto, para finalizar este item, é importante dizer que, em que pesem os dados observados para os empregados permanentes ocupados na cultura da mandioca em 2004 e para os empregados temporários ocupados na cultura da soja no mesmo ano, a tendência mais coerente seria no sentido de que as participações relevantes dos empregados com maior escolaridade ocorreram nas culturas mais dinâmicas (café, cana e soja) para os seus trabalhadores permanentes. 
A polarização da qualidade do emprego na agricultura brasileira no período 1992-2004

\subsection{A polarização nos auxílios recebidos}

Neste item, optou-se por trabalhar com o conjunto dos auxílios recebidos e não com um indicador em separado, como foi feito nos tópicos anteriores. Com isso, fica melhor a visualização a partir do índice parcial de auxílios recebidos, que foi calculado como um dos componentes do Índice de Qualidade do Emprego (IQE).

Para a construção do índice parcial dos auxílios recebidos foram selecionados: porcentagem de empregados que recebiam auxílio-moradia (Auxmor); porcentagem de empregados que recebiam auxílio-alimentação (Auxalim); porcentagem de empregados que recebiam auxílio-transporte (Auxtrans); porcentagem de empregados que recebiam auxílio-educação (Auxeduc); e porcentagem de empregados que recebiam auxílio-saúde (Auxsau). É importante destacar que neste índice parcial foi feita uma diferenciação entre as áreas urbanas e as rurais no tocante à importância relativa dos auxílios recebidos pelos empregados. Assim, para os residentes urbanos, o índice foi calculado da seguinte forma: Indaux $=0,26$ Auxmor $+0,23$ Auxsau $+0,20$ Auxalim $+0,17$ Auxtrans $+0,14$ Auxeduc. Já para os residentes rurais, o cálculo foi feito assim: Indaux $=0,29$ Auxmor + 0,22 Auxsau + 0,20 Auxeduc + 0,17 Auxalim + 0,12 Auxtrans (BALSADI, 2006b).

O índice de auxílios recebidos foi o que menos contribuiu para a melhoria no IQE dos empregados na agricultura brasileira no período 1992-2004 (os de formalidade e de rendimentos foram os mais importantes, seguidos de longe pelo grau de escolaridade). Em função disso, a situação dos empregados permanentes (rurais e urbanos), que já era mais favorável no início dos anos 1990, continuou melhor no ano de 2004.

Pelos dados das Tabelas 8A e 8B, pode-se perceber que o índice parcial calculado para o total de Brasil foi ligeiramente superior no último ano da série, comparativamente ao início da mesma. Os empregados permanentes com residência rural apresentaram o maior valor, um pouco superior ao dos empregados permanentes urbanos. No entanto, ambos os valores estavam bem acima daqueles calculados para os empregados temporários. Esse foi o comportamento-padrão para as regiões e culturas selecionadas. Novamente, a região Nordeste e as culturas de mandioca e milho foram as que apresentaram os menores índices de auxílios recebidos (além do café, em algumas situações, principalmente para os residentes rurais).

Tal comportamento é coerente com o enfraquecimento dos movimentos sindicais, quando muitas cláusulas tidas como sociais foram suprimidas dos contratos coletivos de trabalho. Assim, os empregados permanentes, que possuem um maior nível de formalidade do emprego, conseguiram manter os benefícios, ao passo que os temporários tiveram muita dificuldade em ampliá-los. 
Otávio Valentim Balsadi / José Francisco Graziano da Silva

Tabela 8A

Evolução do Índice Parcial de Auxílios Recebidos pelos Empregados (Indaux), Brasil,

Grandes Regiões e Culturas Selecionadas, 1992-2004

Empregado Permanente

\begin{tabular}{|c|c|c|c|c|c|c|c|c|c|c|c|c|c|c|}
\hline \multirow{2}{*}{$\begin{array}{c}\text { Brasil, Regiões e } \\
\text { Culturas }\end{array}$} & \multicolumn{5}{|c|}{ Urbano } & \multicolumn{2}{|c|}{$\begin{array}{c}\text { Tx. } \\
\text { Cresc.(1) }\end{array}$} & \multicolumn{5}{|c|}{ Rural } & \multicolumn{2}{|c|}{$\begin{array}{c}\text { Tx. } \\
\text { Cresc.(1) }\end{array}$} \\
\hline & 1992 & 1995 & 1998 & 2001 & 2004 & \begin{tabular}{|l|}
$1992-$ \\
2004
\end{tabular} & $\begin{array}{c}2001- \\
2004\end{array}$ & 1992 & 1995 & 1998 & 2001 & 2004 & $\begin{array}{l}1992- \\
2004\end{array}$ & $\begin{array}{l}2001- \\
2004\end{array}$ \\
\hline Brasil & 20,0 & 20,5 & 20,8 & 21,2 & 22,4 & 0,9 & 1,9 & 27,1 & 29,6 & 27,4 & 28,0 & 28,1 & 0,3 & 0,1 \\
\hline \multicolumn{15}{|l|}{ Grandes Regiões } \\
\hline Norte Urbano & 27,2 & 25,9 & 29,8 & 26,0 & 28,0 & 0,2 & 2,5 & - & - & - & - & - & - & - \\
\hline Nordeste & 8,2 & 10,6 & 12,4 & 14,8 & 13,1 & 4,0 & $-4,0$ & 18,6 & 21,0 & 21,6 & 20,7 & 19,9 & 0,6 & $-1,3$ \\
\hline Centro-Oeste & 26,4 & 27,5 & 26,9 & 26,6 & 28,8 & 0,7 & 2,7 & 37,9 & 36,8 & 36,1 & 36,6 & 36,7 & $-0,3$ & 0,1 \\
\hline Sudeste & 17,4 & 17,6 & 16,3 & 15,8 & 19,8 & 1,1 & 7,8 & 24,1 & 27,3 & 23,5 & 28,1 & 25,7 & 0,5 & $-2,9$ \\
\hline Sul & 20,2 & 20,9 & 18,1 & 22,7 & 22,0 & 0,7 & $-1,0$ & 27,7 & 33,0 & 28,5 & 26,5 & 29,8 & 0,6 & 4,0 \\
\hline \multicolumn{15}{|l|}{ Culturas } \\
\hline Arroz & 24,8 & 16,2 & 15,2 & 19,4 & 28,2 & 1,1 & 13,3 & 23,2 & 25,8 & 25,0 & 22,5 & 27,1 & 1,3 & 6,4 \\
\hline Café & 8,7 & 12,8 & 13,6 & 11,7 & 14,0 & 4,0 & 6,2 & 22,5 & 22,9 & 24,5 & 28,0 & 25,6 & 1,1 & $-2,9$ \\
\hline Cana-de-açúcar & 13,3 & 18,9 & 16,0 & 16,5 & 22,5 & 4,5 & 10,9 & 21,4 & 27,2 & 27,2 & 21,6 & 23,8 & 0,9 & 3,3 \\
\hline Mandioca & 6,8 & 12,1 & 11,0 & 19,8 & 14,6 & 6,6 & $-9,7$ & 16,4 & 18,7 & 13,7 & 14,5 & 9,7 & $-4,3$ & $-12,5$ \\
\hline Milho & 8,5 & 12,0 & 14,5 & 14,3 & 19,5 & 7,2 & 10,9 & 20,6 & 21,3 & 19,4 & 17,8 & 21,2 & 0,2 & 6,0 \\
\hline Soja & 27,2 & 23,4 & 25,7 & 27,6 & 26,5 & $-0,2$ & $-1,3$ & 36,0 & 34,1 & 36,7 & 33,4 & 33,9 & $-0,5$ & 0,5 \\
\hline
\end{tabular}

Tabela 8B

Evolução do Índice Parcial de Auxílios Recebidos pelos Empregados (Indaux), Brasil, Grandes Regiões e Culturas Selecionadas, 1992-2004

Empregado Temporário

\begin{tabular}{|c|c|c|c|c|c|c|c|c|c|c|c|c|c|c|}
\hline \multirow{2}{*}{$\begin{array}{c}\text { Brasil, Regiões e } \\
\text { Culturas }\end{array}$} & \multicolumn{5}{|c|}{ Urbano } & \multicolumn{2}{|c|}{$\begin{array}{c}\text { Tx. } \\
\text { Cresc.(1) }\end{array}$} & \multicolumn{5}{|c|}{ Rural } & \multicolumn{2}{|c|}{$\begin{array}{c}\text { Tx. } \\
\text { Cresc.(1) }\end{array}$} \\
\hline & 1992 & 1995 & 1998 & 2001 & 2004 & $\begin{array}{l}1992- \\
2004\end{array}$ & $\begin{array}{c}2001- \\
2004\end{array}$ & 1992 & 1995 & 1998 & 2001 & 2004 & $\begin{array}{l}1992- \\
2004\end{array}$ & $\begin{array}{l}2001- \\
2004\end{array}$ \\
\hline Brasil & 12,6 & 14,5 & 13,8 & 13,6 & 13,4 & 0,5 & $-0,5$ & 8,9 & 9,0 & 9,3 & 9,3 & 9,5 & 0,5 & 0,7 \\
\hline
\end{tabular}

Grandes Regiões

\begin{tabular}{l|r|r|r|r|r|r|r|r|r|r|r|r|r|r}
\hline Norte Urbano & 18,0 & 22,9 & 23,8 & 21,0 & 18,9 & 0,4 & $-3,5$ & - & - & - & - & - & - & - \\
\hline Nordeste & 6,3 & 6,9 & 5,8 & 7,6 & 8,6 & 2,6 & 4,2 & 5,6 & 6,4 & 4,7 & 6,5 & 6,8 & 1,6 & 1,5 \\
\hline Centro-Oeste & 18,6 & 18,9 & 16,0 & 19,0 & 16,4 & $-1,0$ & $-4,8$ & 13,6 & 11,6 & 13,5 & 15,1 & 12,8 & $-0,5$ & $-5,4$ \\
\hline Sudeste & 10,2 & 11,7 & 11,7 & 10,7 & 12,6 & 1,8 & 5,6 & 8,0 & 6,2 & 7,5 & 6,9 & 9,0 & 1,0 & 9,3 \\
\hline Sul & 9,9 & 11,9 & 11,3 & 9,6 & 10,3 & 0,3 & 2,4 & 8,4 & 11,5 & 11,3 & 8,7 & 9,1 & 0,7 & 1,5 \\
\hline
\end{tabular}

Culturas

\begin{tabular}{l|r|r|r|r|r|r|r|r|r|r|r|r|r|r}
\hline Arroz & 10,2 & 12,6 & 11,5 & 15,4 & 15,8 & 3,7 & 0,9 & 8,5 & 9,6 & 10,6 & 8,1 & 11,1 & 2,2 & 11,1 \\
\hline Café & 9,1 & 9,5 & 12,9 & 8,5 & 10,1 & 0,9 & 5,9 & 7,6 & 10,0 & 9,1 & 8,7 & 7,7 & 0,1 & $-4,0$ \\
\hline Cana-de-açúcar & 13,7 & 16,5 & 14,5 & 16,1 & 14,0 & 0,2 & $-4,6$ & 12,4 & 12,1 & 12,6 & 10,9 & 14,2 & 1,1 & 9,2 \\
\hline Mandioca & 9,6 & 5,5 & 6,4 & 7,0 & 6,3 & $-3,4$ & $-3,5$ & 2,9 & 5,4 & 3,4 & 4,3 & 3,0 & 0,3 & $-11,3$ \\
\hline Milho & 6,9 & 7,7 & 9,5 & 7,5 & 7,0 & 0,1 & $-2,3$ & 7,6 & 5,4 & 5,9 & 5,2 & 7,4 & $-0,2$ & 12,5 \\
\hline Soja & 13,8 & 12,6 & 18,2 & 15,0 & 24,0 & 4,7 & 17,0 & 22,2 & 10,8 & 12,8 & 19,7 & 14,3 & $-3,6$ & $-10,1$ \\
\hline
\end{tabular}

Nota: (1) Taxa geométrica de crescimento, em \% a.a.

Fonte: Elaboração dos autores a partir dos microdados da PNAD. 
É sempre bom lembrar que: o auxílio-moradia é o mais relevante para os empregados permanentes com residência rural, seguido pelo auxílio-alimentação; os auxílios alimentação, transporte e moradia, têm participações relativamente próximas para os permanentes urbanos, com maior destaque para o primeiro; os auxílios alimentação e transporte são os mais relevantes para os temporários urbanos; o auxílio-alimentação é, destacadamente, o mais importante para os temporários rurais; o auxílio-educação é inexpressivo em todas as categorias; e o auxílio-saúde tem maior relevância para os empregados permanentes urbanos e rurais, principalmente para aqueles ocupados nas culturas da cana, da soja e do café.

\subsection{O ranking para o Índice de Qualidade do Emprego (IQE)}

Após as análises para o total de Brasil, para as cinco Grandes Regiões e para as seis culturas selecionadas, pode-se fazer um ranking do Índice de Qualidade do Emprego (IQE), de modo a se saber qual categoria de empregado, em qual região e qual cultura, apresentou, dentro dos limites metodológicos adotados, a melhor qualidade do emprego agrícola.

De acordo com Balsadi (2006a), para construir o IQE, os procedimentos básicos são os seguintes: obtenção dos indicadores simples; construção dos índices parciais, a partir das médias ponderadas dos indicadores simples, no sentido de captar as dimensões da qualidade do emprego; cálculo do IQE a partir das médias ponderadas dos índices parciais.

A seguir, são descritos os indicadores simples e os índices parciais para as quatro dimensões selecionadas para avaliar a evolução da qualidade do emprego agrícola: nível educacional dos empregados; grau de formalidade do emprego; rendimento recebido no trabalho principal; e auxílios recebidos pelos empregados.

Para analisar o nível educacional das pessoas empregadas, foram selecionados indicadores relacionados a dois aspectos: alfabetização e nível de escolaridade. Para isso, foram escolhidos os seguintes indicadores simples: porcentagem de pessoas empregadas não analfabetas ou com mais de um ano de estudo (Indalf); porcentagem de pessoas ocupadas com até quatro anos de estudo (Indesc1); e porcentagem de pessoas ocupadas com oito ou mais anos de estudo (Indesc2). Assim, o índice parcial de educação foi calculado da seguinte forma, com o auxílio da técnica de análise multicritério: Indeduc $=0,45$ Indesc $2+0,36$ Indesc $1+0,19$ Indalf.

$\mathrm{Na}$ formalidade do emprego, foram selecionados: porcentagem de empregados com idade acima de 15 anos, o que representa a proporção de trabalhadores não infantis empregada (Ninf); porcentagem de empregados com jornada semanal de até 44 horas, o que corresponde à participação dos empregados sem sobretrabalho (Jorn); porcentagem de empregados com carteira assinada 
(Cart); e porcentagem de empregados contribuintes da Previdência Social (Prev). O índice parcial de formalidade foi calculado da seguinte forma: Indformal $=0,35$ Cart + 0,29 Prev + 0,24 Ninf + 0,12 Jorn.

Para o rendimento obtido no trabalho principal foram selecionadas a porcentagem de empregados com remuneração acima de um salário mínimo (Npob) e o rendimento médio mensal (Rend). $\mathrm{O}$ índice parcial de rendimento foi calculado da seguinte forma: Indrend $=0,60 \mathrm{Npob}+0,40$ Rend. Nos auxílios recebidos foram selecionados os mesmos indicadores já descritos no item 2.4. A Polarização nos Auxílios Recebidos. De todos os indicadores selecionados, apenas o rendimento médio mensal precisou ser padronizado para variar de 0 a 100 , segundo a fórmula: ((valor - mínimo)/(máximo - mínimo)), onde o mínimo e o máximo são, respectivamente, os valores mínimo e máximo do rendimento médio encontrados em toda a série, possibilitando a comparação intertemporal.

Os IQEs obtidos são passíveis de comparação intertemporal. Para a comparação, trabalhou-se com a idéia de progresso relativo, calculado pela fórmula:

$$
\frac{\text { valor do índice em t } 1-\text { valor em t } 0}{100-\text { valor em t } 0}
$$

O denominador mostra o máximo crescimento que seria possível a partir do ano inicial (progresso possível) e o numerador indica o crescimento obtido de fato no período considerado (progresso efetivo). A razão entre os dois valores compreende a velocidade relativa da melhoria nas condições e qualidade do emprego (Kageyama; Rehder, 1993).

Com o auxílio de técnicas de multicritério, o cálculo final do índice foi feito da seguinte forma: $\mathrm{IQE}=0,35$ Indrend + 0,29 Indformal + 0,21 Indeduc + 0,15 Indaux, onde os índices parciais são, respectivamente, os de rendimento, de grau de formalidade, de nível educacional dos empregados e de auxílios recebidos pelos empregados (Balsadi, 2006b).

O Apoio Multicritério à Decisão (AMD) consiste em um conjunto de métodos e técnicas para auxiliar ou apoiar pessoas e organizações a tomarem decisões, quando da presença de uma multiplicidade de critérios. No AMD, são construídos modelos que legitimam os juízos de valor subjetivos. Ou seja, pressupõe aceitar que a subjetividade está presente em todo o processo de decisão, pois é consensual que nenhum método consegue eliminá-la totalmente, especialmente no processo de definição das estruturas de ponderação.

Em AMD, os juízos de valor dos decisores são expressos por meio de suas estruturas de preferência entre pares de alternativas ou critérios. As quatro relações fundamentais são indiferença, preferência estrita, preferência fraca e 
A polarização da qualidade do emprego na agricultura brasileira no período 1992-2004

incomparabilidade. A forma de explicitar as estruturas de preferência do decisor varia de acordo com o método de análise multicritério escolhido. Para a construção do IQE e do ICV, foi escolhido um método da escola americana de multicritério, o Macbeth (Measuring Attractiveness by a Categorical Based Evaluation Technique). ${ }^{7}$

A escolha do referido método foi baseada nos seguintes motivos principais: decisão de atribuir pesos diferenciados para os indicadores e dimensões selecionados; existência e disponibilidade de um bom conjunto de indicadores; constituir-se em uma solução intermediária entre o total empirismo e as sofisticadas técnicas de econometria, nem sempre muito familiares; disponibilidade e facilidade no uso e na compreensão tanto do método em si quanto do programa computacional que o executa; forte interação entre o especialista (decisor) e o programa, permitindo ajustes nos pesos propostos; realização de testes de consistência em todos os critérios utilizados na definição da estrutura de ponderação.

O método Macbeth permite agregar os diversos critérios de avaliação em um critério único de síntese por meio da atribuição de pesos aos vários critérios, respeitando as opiniões dos decisores. Por meio da comparação par a par da atratividade das alternativas, são atribuídos os pesos aos critérios: dadas duas alternativas, o decisor deve dizer qual a mais atrativa (deve receber a maior nota) e qual o grau dessa atratividade em uma escala semântica que tem correspondência com uma escala ordinal $(0=$ indiferente, $1=$ diferença de atratividade muito fraca, $2=$ diferença de atratividade fraca, 3 = diferença de atratividade moderada, $4=$ diferença de atratividade forte, $5=$ diferença de atratividade muito forte e $6=$ diferença de atratividade extrema).

O ranking do IQE, feito com base em 2005, é apresentado na Tabela 9. Pode-se observar que a região Centro-Oeste apresentou os dois melhores IQEs regionais, com os empregados permanentes rurais, em primeiro, e os empregados permanentes urbanos, em segundo. A seguir, vieram os empregados permanentes urbanos da região Sul, os empregados permanentes urbanos da região Sudeste e os empregados permanentes rurais da região Sul. Essas cinco categorias tiveram IQE acima do melhor IQE calculado para o total de Brasil, que foi o dos empregados permanentes urbanos.

Por outro lado, a região Nordeste apresentou os dois piores IQEs, obtidos para os empregados temporários urbanos e para os empregados temporários rurais. É interessante notar que o melhor IQE da região Nordeste, dos empregados permanentes urbanos, só é maior que o IQE das categorias de empregados

(7) Para maiores detalhes sobre o Macbeth, ver Balsadi (2006b), onde constam várias referências sobre esse método de análise multicritério.

Economia e Sociedade, Campinas, v. 17, n. 3 (34), p. 493-524, dez. 2008. 
temporários das demais regiões e culturas (as exceções são os permanentes rurais empregados na cultura do milho e os permanentes urbanos e rurais empregados na cultura da mandioca, além dos próprios permanentes rurais da região Nordeste). Ou seja, na média, a melhor condição de emprego no Nordeste é relativamente próxima às piores condições de emprego nas demais regiões e culturas, o que ainda mantém aceso o debate sobre a urgente necessidade de políticas para a redução das desigualdades regionais.

Entre as culturas selecionadas, é possível perceber que a soja foi a que apresentou os melhores IQEs, com os empregados permanentes urbanos e rurais. A seguir, vieram os empregados permanentes rurais ocupados na cultura do arroz, os empregados permanentes urbanos ocupados na cultura da cana-de-açúcar e os empregados permanentes urbanos ocupados na cultura do arroz. Essas cinco categorias também ficaram acima do melhor IQE agregado para o Brasil, que foi o dos empregados permanentes urbanos.

Tabela 9

Índice de Qualidade do Emprego (IQE) e Progresso Relativo dos Empregados Permanentes e dos Temporários

Brasil, Grandes Regiões e Culturas, 1992-2004

\begin{tabular}{l|c|c|c|c|c|c}
\hline \multirow{2}{*}{ Categorias } & \multicolumn{3}{|c}{ IQE } & Prog. Rel. \\
\cline { 2 - 7 } & 1992 & 1995 & 1998 & 2001 & 2004 & $1992-04(\%)$ \\
\hline Empregado Permanente Urbano - Soja & 49,6 & 57,2 & 54,1 & 53,5 & 64,8 & 30,2 \\
\hline Empregado Permanente Rural - Soja & 56,9 & 55,6 & 66,7 & 61,0 & 60,9 & 9,4 \\
\hline Empregado Permanente Rural - Arroz & 43,2 & 43,1 & 52,1 & 42,9 & 59,5 & 28,7 \\
\hline Empregado Permanente Urbano - Cana & 47,4 & 53,0 & 55,7 & 57,4 & 58,4 & 21,0 \\
\hline Empregado Permanente Rural - Centro-Oeste & 43,5 & 47,1 & 52,7 & 55,8 & 58,1 & 25,9 \\
\hline Empregado Permanente Urbano - Centro-Oeste & 40,6 & 46,8 & 50,3 & 52,3 & 56,0 & 25,9 \\
\hline Empregado Permanente Urbano - Sul & 50,3 & 49,5 & 51,1 & 47,7 & 54,0 & 7,5 \\
\hline Empregado Permanente Urbano - Sudeste & 45,1 & 49,0 & 49,5 & 51,4 & 52,8 & 14,0 \\
\hline Empregado Permanente Rural - Sul & 45,3 & 49,4 & 51,3 & 49,1 & 52,4 & 13,0 \\
\hline Empregado Permanente Urbano - Arroz & 45,2 & 48,7 & 49,8 & 48,0 & 50,2 & 9,1 \\
\hline Empregado Permanente Urbano - Brasil & $\mathbf{3 8 , 8}$ & $\mathbf{4 2 , 5}$ & $\mathbf{4 5 , 2}$ & $\mathbf{4 4 , 9}$ & $\mathbf{4 8 , 3}$ & $\mathbf{1 5 , 6}$ \\
\hline Empregado Temporário Urbano - Cana & 38,0 & 45,1 & 44,2 & 46,5 & 47,5 & 15,3 \\
\hline Empregado Permanente Urbano - Café & 29,3 & 40,7 & 44,1 & 43,6 & 46,2 & 24,0 \\
\hline Empregado Permanente Rural - Brasil & $\mathbf{3 6 , 9}$ & $\mathbf{4 2 , 5}$ & $\mathbf{4 4 , 6}$ & $\mathbf{4 4 , 8}$ & $\mathbf{4 6 , 0}$ & $\mathbf{1 4 , 4}$ \\
\hline Empregado Permanente Urbano - Norte & 31,6 & 38,7 & 41,3 & 40,3 & 45,8 & 20,7 \\
\hline Empregado Permanente Rural - Sudeste & 37,8 & 45,5 & 45,6 & 46,5 & 45,3 & 12,1 \\
\hline Empregado Permanente Rural - Cana & 38,5 & 46,9 & 46,2 & 41,7 & 42,7 & 6,9 \\
\hline Empregado Permanente Rural - Café & 33,8 & 41,4 & 43,2 & 43,1 & 42,0 & 12,3 \\
\hline Empregado Temporário Urbano - Sudeste & 29,0 & 39,2 & 38,5 & 36,4 & 42,0 & 18,2 \\
\hline Empregado Temporário Urbano - Soja & 28,0 & 35,1 & 34,1 & 33,8 & 39,7 & 16,3 \\
\hline Empregado Permanente Urbano - Milho & 25,4 & 34,7 & 33,3 & 36,4 & 38,1 & 17,0 \\
\hline Empregado Permanente Urbano - Nordeste & 25,2 & 30,2 & 34,9 & 33,1 & 36,0 & 14,4 \\
\hline Empregado Temporário Urbano - Centro-Oeste & 28,8 & 33,3 & 35,1 & 36,6 & 36,0 & 10,1 \\
\hline Empregado Temporário Urbano - Café & 20,0 & 33,2 & 36,6 & 28,2 & 34,6 & 18,3 \\
\hline & & & & & & Continua... \\
\hline
\end{tabular}


A polarização da qualidade do emprego na agricultura brasileira no período 1992-2004

\begin{tabular}{|c|c|c|c|c|c|c|}
\hline \multirow{2}{*}{ Categorias } & \multicolumn{5}{|c|}{ IQE } & \multirow{2}{*}{$\begin{array}{c}\text { Prog. Rel. } \\
\text { 1992-04 (\%) }\end{array}$} \\
\hline & 1992 & 1995 & 1998 & 2001 & 2004 & \\
\hline Empregado Temporário Rural - Cana & 25,6 & 30,4 & 35,8 & 28,5 & 33,0 & 9,9 \\
\hline Empregado Temporário Urbano - Brasil & 25,8 & 32,4 & 30,8 & 29,7 & $\mathbf{3 1 , 5}$ & 7,7 \\
\hline Empregado Temporário Rural - Centro-Oeste & 23,6 & 31,7 & 29,2 & 30,1 & 31,2 & 10,1 \\
\hline Empregado Permanente Rural - Milho & 24,9 & 29,3 & 31,3 & 30,6 & 31,1 & 8,3 \\
\hline Empregado Permanente Rural - Nordeste & 23,7 & 29,3 & 30,4 & 30,5 & 31,1 & 9,7 \\
\hline Empregado Temporário Urbano - Norte & 26,1 & 33,3 & 28,5 & 30,2 & 30,6 & 6,1 \\
\hline Empregado Temporário Rural - Soja & 32,0 & 30,8 & 29,9 & 25,6 & 29,7 & $-3,5$ \\
\hline Empregado Temporário Rural - Café & 16,9 & 31,1 & 31,1 & 23,2 & 28,6 & 14,0 \\
\hline Empregado Temporário Rural - Sul & 23,0 & 29,0 & 28,3 & 25,7 & 27,2 & 5,5 \\
\hline Empregado Temporário Urbano - Sul & 24,2 & 34,3 & 32,8 & 27,1 & 27,2 & 3,9 \\
\hline Empregado Temporário Rural - Sudeste & 20,0 & 26,7 & 27,7 & 23,5 & 26,5 & 8,1 \\
\hline Empregado Permanente Urbano - Mandioca & 22,1 & 24,1 & 31,9 & 29,4 & 26,1 & 5,1 \\
\hline Empregado Temporário Urbano - Milho & 17,6 & 25,0 & 25,6 & 22,4 & 25,6 & 9,7 \\
\hline Empregado Temporário Rural - Brasil & 19,8 & 25,9 & 25,4 & 23,6 & 25,2 & 6,7 \\
\hline Empregado Temporário Urbano - Arroz & 21,3 & 28,0 & 25,7 & 22,0 & 25,0 & 4,7 \\
\hline Empregado Permanente Rural - Mandioca & 17,6 & 19,1 & 21,5 & 27,7 & 23,4 & 7,1 \\
\hline Empregado Temporário Urbano - Mandioca & 19,1 & 24,1 & 20,5 & 18,9 & 22,8 & 4,5 \\
\hline Empregado Temporário Rural - Arroz & 18,8 & 25,1 & 23,0 & 21,6 & 22,2 & 4,2 \\
\hline Empregado Temporário Urbano - Nordeste & 19,2 & 22,0 & 18,6 & 19,8 & 22,1 & 3,6 \\
\hline Empregado Temporário Rural - Nordeste & 15,6 & 19,0 & 18,6 & 17,7 & 19,7 & 4,9 \\
\hline Empregado Temporário Rural - Milho & 15,5 & 20,0 & 20,6 & 18,9 & 19,1 & 4,3 \\
\hline Empregado Temporário Rural - Mandioca & 14,5 & 16,5 & 17,9 & 15,9 & 16,6 & 2,6 \\
\hline
\end{tabular}

Fonte: Elaboração dos autores a partir dos Microdados da PNAD.

No outro extremo, as seis categorias com IQE abaixo do pior IQE agregado para o Brasil, que foi para os empregados temporários rurais, foram as seguintes: empregado temporário urbano ocupado na cultura do arroz; empregado permanente rural ocupado na cultura da mandioca; empregado temporário urbano ocupado na cultura da mandioca; empregado temporário rural ocupado na cultura do arroz; empregado temporário rural ocupado na cultura do milho; e empregado temporário rural ocupado na cultura da mandioca. E o IQE dessas categorias está muito distante dos melhores IQEs (quando muito, chegam à metade do valor, como é o caso dos temporários rurais ocupados no arroz, em relação aos permanentes urbanos ocupados nessa mesma cultura).

Ou seja, os dados obtidos para o IQE mostram claramente que as melhores condições de emprego estavam, de forma geral, nas culturas mais dinâmicas e de comércio exterior e para os empregados permanentes, em 2004 e ao longo de, praticamente, todo o período. Entre os dez melhores IQEs (excluindo-se os valores agregados para o total de Brasil e Grandes Regiões - ou seja, ficando-se apenas com as culturas), oito são para empregados permanentes (quatro urbanos e quatro rurais) e apenas dois para empregados temporários (ambos urbanos), três são para a cultura da soja, três também para a cultura da cana-de-açúcar, dois para o café e dois para o arroz. 
Por outro lado, entre os dez piores IQEs, oito são para empregados temporários (cinco rurais e três urbanos) e apenas dois para empregados permanentes (um rural e um urbano), quatro são para a cultura da mandioca, dois para o arroz, dois para o milho, um para o café e um para a cultura da soja.

\section{Considerações finais}

O principal objetivo do artigo foi mostrar a polarização na qualidade do emprego no mercado de trabalho assalariado agrícola no período 1992-2004, entre as categorias de empregados permanentes e empregados temporários.

À luz dos estudos e pesquisas realizados por especialistas em mercado de trabalho urbano, desde a primeira metade dos anos 1990, procurou-se mostrar a polarização no mercado de trabalho assalariado agrícola com base em um conjunto de indicadores selecionados, bem como com base no próprio Índice de Qualidade do Emprego (IQE) construído. Foi possível concluir que a polarização está presente no agregado de Brasil, entre as regiões, entre as culturas selecionadas e mesmo entre as mesmas categorias de empregados. Ou seja, um empregado permanente ou temporário ocupado em uma commodity está em melhores condições do que um ocupado nas culturas mais tradicionais. O ranking construído para o IQE foi muito claro e elucidativo nesse sentido.

A partir de tais resultados, pode-se colocar a seguinte questão: o que influi na polarização do mercado de trabalho assalariado na agricultura? Ainda à guisa de conclusões mais seguras, poderiam ser elencados, por um lado, os fatores mais abrangentes observados no mercado de trabalho em geral, e, por outro, alguns fatores mais específicos da agricultura brasileira no período. Entre os primeiros, estão: o aumento da heterogeneidade do mercado de trabalho; a tendência à precarização das relações de trabalho, com o aumento das desigualdades entre as categorias de trabalhadores e a dificuldade de expansão das atividades formais vis$\grave{a}$-vis as informais; o menor ritmo de crescimento das ocupações mais bem remuneradas e mais exigentes em qualificação vis-à-vis a forte expansão das ocupações mais precárias, que, mesmo fazendo uso de uma mão-de-obra mais escolarizada, normalmente o faz para atividades rotineiras e de pouca criatividade; e a continuidade do processo de reestruturação produtiva e de incorporação de modernas tecnologias, quase sempre poupadoras de força de trabalho, visando ampliar os ganhos de produtividade e aumentar a competitividade.

Dentre os fatores mais específicos da agricultura, poderiam ser citados os seguintes, sem nenhuma pretensão de esgotá-los ou hierarquizá-los:

- a crescente especialização na produção das principais commodities, que são componentes importantes da pauta de exportações brasileira; 
A polarização da qualidade do emprego na agricultura brasileira no período 1992-2004

- a marcante diferença de rentabilidade das atividades mais dinâmicas vis-àvis as mais tradicionais, sendo que as últimas têm enormes dificuldades em formalizar e remunerar bem a força de trabalho, tanto a contratada quanto a familiar;

- o processo de modernização e mecanização que se aprofundou na agricultura de grande escala, a qual emprega poucos trabalhadores qualificados (quando emprega!) e muitos com baixa qualificação;

- a crescente importância do processo de externalização ou terceirização das atividades agrícolas para as empresas prestadoras de serviços na agricultura;

- a maior fiscalização por parte dos órgãos nacionais nas empresas agrícolas de maior porte, exportadoras ou não, para evitar abusos e desrespeitos aos direitos sociais, trabalhistas e ambientais, o que as obrigou a melhor cumprir a legislação trabalhista;

- a crescente busca por certificações (diversas modalidades da ISO) que garantam uma melhor inserção dos produtos agropecuários em mercados mais exigentes, o que tem efeitos positivos na melhoria da qualidade do trabalho nas atividades econômicas mais sustentáveis;

- o aparecimento e/ou expansão de algumas "novas profissões", como é o caso do especialista em manejo integrado de pragas, dos operadores das novas máquinas e implementos agrícolas, do especialista em produção agroecológica, do especialista em inseminação artificial e reprodução animal, do especialista em qualidade do produto nas fases de colheita e pós-colheita, entre outras - vale dizer que essas "profissões" contrastam com a grande maioria da força de trabalho utilizada nas tradicionais atividades ligadas aos tratos culturais e à colheita, por exemplo, tanto em termos de formalidade quanto de remuneração;

- a grande importância que ainda tem a mão-de-obra temporária nas atividades agropecuárias, especialmente na colheita de algumas grandes culturas (cana, laranja, café, mandioca, para citar algumas) - em muitas atividades, ela é muito superior à mão-de-obra permanente;

- a fraca representação e organização sindical dessa categoria de trabalhadores temporários, com exceção de algumas culturas em algumas regiões produtoras.

Estes dois últimos fatores reforçam e tornam muito atual o argumento defendido por Graziano da Silva (1997) de que a formação e a estruturação dos sindicatos específicos de assalariados agrícolas são muito importantes para o fortalecimento de todas as categorias de trabalhadores na agricultura. Se os empregados permanentes estão em situação mais favorável, é inexorável admitir que ainda são necessárias políticas públicas e ações dos trabalhadores e dos 
agricultores no sentido de proporcionar melhores condições de trabalho para os empregados temporários, os quais possuem níveis muito elevados de precarização.

Também é importante registrar a importância das políticas pró-emprego e de recomposição do mercado de trabalho formal. Para isso, o Estado deve ser mais pró-ativo, de forma a contrapor a tendência fortemente excludente das livres forças do mercado. E os dados de geração de empregos com carteira assinada na agricultura no período 2001-2004 (e também na economia como um todo) reforçam que, de fato, há espaços e margem de manobra para a geração de ocupações com maior qualidade no mercado de trabalho assalariado brasileiro.

A maior atuação do Estado, nos seus três níveis de governo (federal, estadual e municipal) deveria ser marcada pelo desenho e implantação de políticas de desenvolvimento local/regional que priorizem a geração de empregos, de políticas de apoio efetivo às atividades tradicionais para que possam aumentar a sua produtividade e rentabilidade e, com isso, oferecer melhores condições de emprego, de políticas sérias de qualificação e requalificação profissional, de políticas de financiamento para os excluídos pelas reestruturações produtivas, por meio do microcrédito e da economia solidária, de políticas de fortalecimento da representação sindical, etc. Obviamente, todas essas políticas devem ser potencializadas por um contexto macroeconômico favorável ao crescimento econômico e ao desenvolvimento com distribuição de renda.

Em trabalho recente, Salm (2004) reforça as seguintes recomendações para uma política efetiva de emprego no Brasil, que poderá reduzir a polarização da qualidade do mesmo: incentivar a formalização das médias e pequenas empresas (MPE) por meio da adequação da estrutura tributária e das legislações trabalhista e previdenciária; induzir e apoiar a formação de Arranjos Produtivos Locais (APL) capazes de competir nos cenários nacional e mundial; estimular o aumento da produtividade e da demanda de produtos de consumo popular por meio de medidas redistributivas (aumento real do salário mínimo, transferência direta de renda, gastos assistenciais, estrutura tributária, etc.); e diminuir, por meio da transferência de renda, a pressão da oferta de mão-de-obra não qualificada sobre o mercado de trabalho, principalmente aquela exercida por jovens subescolarizados e mães que são chefes de família.

Finalmente, vale dizer que o tema da polarização no mercado de trabalho agrícola merece mais estudos aprofundados, de preferência com pesquisas de campo. Os passos percorridos neste artigo, que enfocou o mercado de trabalho assalariado na agricultura brasileira no período 1992-2004, podem ser bastante úteis na identificação de novos estudos numa temática em que as pesquisas acadêmicas são absolutamente raras. 
A polarização da qualidade do emprego na agricultura brasileira no período 1992-2004

\section{Referências bibliográficas}

ANDRADE, A. S. de C. Trabalho feminino e desvantagem social: diferenciais de raça/cor no emprego doméstico. In: ENCONTRO NACIONAL DE ESTUDOS POPULACIONAIS, 14, 2004, Caxambu. Caxambu: Anpocs, 2004. 17p.

ARAÚJO, M. de F. I. Reestruturação produtiva e transformações econômicas: Região Metropolitana de São Paulo. São Paulo em Perspectiva, São Paulo, Seade, v. 15, n. 1, p. 20-30, jan./mar. 2001.

BALSADI, O. V. Qualidade do emprego na agropecuária brasileira no período 20012004. Parcerias Estratégicas, Brasília, n. 22, p. 245-281, 2006 a.

O mercado de trabalho assalariado na agricultura brasileira no período 1992 2004 e suas diferenciações regionais. 2006b. Tese (Doutorado). Instituto de Economia, Universidade Estadual de Campinas.

BALSADI, O. V.; BORIN, M. R.; SILVA, J. G. da; BELIK, W. Transformações tecnológicas e a força de trabalho na agricultura brasileira no período 1990-2000. Agricultura em São Paulo, São Paulo, v. 49, n. 1, p. 23-40, 2002.

BELIK, W.; BALSADI, O. V.; DEL GROSSI, M. E.; BORIN, M. R.; CAMPANHOLA, C.; GRAZIANO DA SILVA, J. O emprego rural nos anos 90. In: PRONI, M. W.; HENRIQUE, W. (Org.). Trabalho, mercado e sociedade: o Brasil nos anos noventa. São Paulo: Ed. Unesp, Instituto de Economia da Unicamp, 2003.

BRANDÃO, A. S. P.; REZENDE, G. C. de; MARQUES, R. W. da C. Crescimento agrícola no período 1999-2004, explosão da área plantada com soja e meio ambiente no Brasil. Rio de Janeiro: Ipea, 2005. 21p. (Texto para Discussão, n. 1062).

CAMPANHOLA, C.; GRAZIANO DA SILVA, J. (Ed.). O novo rural brasileiro: uma análise nacional e regional. Jaguariúna, SP: Embrapa Meio Ambiente, 2000. v. 1.

CENTRO BRASILEIRO DE ANÁLISES E PESQUISAS. Reestruturação produtiva e mercado de trabalho. Cadernos de Pesquisa, São Paulo, Cebrap, n. 1, p. 29-59, jun. 1994.

CONTINI, E.; GASQUES, J. G.; LEONARDI, R. B. de A.; BASTOS, E. T. Evolução recente e tendências do agronegócio. Revista de Política Agrícola, Brasília, DF, ano 15, n. 1, p. 5-28, jan./mar. 2006.

DEDECCA. C. S. O desemprego é um problema específico das grandes metrópoles? Como ele pode ser contornado? DiverCidade (Revista Eletrônica do Centro de Estudos da Metrópole), n. 4, p. 1-2. Disponível em: <http://www.centrodametropole.org.br/divercidade/numero4/> Acesso em: 01 set. 2006.

; ROSANDISKI, E. N. Recuperação econômica e a geração de empregos formais. Campinas: IE/Unicamp, 2006. 20p. Mimeografado.

FERREIRA, B.; BALSADI, O. V.; FREITAS, R. E.; ALMEIDA, A. N. de. Ocupações agrícolas e não-agrícolas: trajetória e rendimentos no meio rural brasileiro. In: DE NEGRI, J. A.; DE NEGRI, F.; COELHO, D. (Org.). Tecnologia, exportação e emprego. Brasília, DF: Ipea, 2006. Cap. 15, p. 445-488.

FERREIRA FILHO, J. B. de S. Mudança tecnológica e a estrutura da demanda por trabalho na agricultura brasileira. In: WORKSHOP MERCADO DE TRABALHO DO 
Otávio Valentim Balsadi / José Francisco Graziano da Silva

SETOR SUCROALCOOLEIRO - DESAFIOS E PERSPECTIVAS FUTURAS, 2004, Piracicaba. Piracicaba: Esalq/USP, 2004. 13p.

GASQUES, J. G.; BASTOS, E. T.; BACCHI, M. P. R.; CONCEIÇÃO, J. C. P. R. Condicionantes da produtividade da agropecuária brasileira. Brasília, DF: Ipea, 2004a. 30p. (Texto para Discussão, n. 1017).

; REZENDE, G. C. de; VILLA VERDE, C. M.; SALERNO, M. S.; CONCEIÇÃO, J. C. P. R.; CARVALHO, J. C. de S. Desempenho e crescimento do agronegócio no Brasil. Brasília, DF: Ipea, 2004b. 40 p. (Texto para Discussão, n. 1009).

GODOY, A. M. G. Reestruturação produtiva e polarização do mercado de trabalho em Paranaguá. Revista Paranaense de Desenvolvimento, Curitiba, n. 99, p. 5-25, jul./dez. 2000.

GRAZIANO DA SILVA, J. De bóias-frias a empregados rurais - as greves dos canavieiros paulistas de Guariba e de Leme. Alagoas: EDUFAL, 1997.

HOFFMANN, R.; KAGEYAMA, A. A dupla natureza da pobreza no Brasil e sua trajetória na última década. Campinas, Unicamp. IE, jun. 2005. 105p. (Relatório de Pesquisa).

KAGEYAMA, A.; REHDER, P. O bem-estar rural no Brasil na década de oitenta. Revista de Economia e Sociologia Rural, Brasília, DF, v. 31, n. 1, p. 23-44. jan./mar. 1993.

MUELLER, C. C. Agricultura e desenvolvimento agrário e o Governo Lula. Brasília, DF: Departamento de Economia/UNB, 2005. 24p. Mimeografado.

REZENDE, G. C. de. Políticas trabalhista e fundiária e seus efeitos adversos sobre o emprego agrícola, a estrutura agrária e o desenvolvimento territorial rural no Brasil. Rio de Janeiro: Ipea, 2005. 31p. (Texto para Discussão, n. 1108).

SALM, C. Crescimento sustentado e política de emprego. Rio de Janeiro: Instituto Nacional de Altos Estudos (Inae), 2004. 10p. (Estudos e Pesquisas, n. 65).

SCORZAFAVE, L. G.; MENEZES-FILHO, N. A. Famílias trabalhadoras e famílias sem trabalho: evidências de polarização para o Brasil. In: ENCONTRO NACIONAL DE ECONOMIA, 33, 2005, Natal. Anais... Natal: Anpec, 2005.

SOJA, E. W. Tensões urbanas: globalização, reestruturação industrial e a transição pósmetropolitana. Belo Horizonte: Escola de Governo Prof. Paulo Neves de Carvalho, 2001. 7p. Mimeografado.

TAPIA, J. R. B.; GOMES, E. R. Concertações sociais, integração européia e a reforma da regulação social: redefinindo a agenda clássica do neocorporativismo. In: ENCONTRO DA ASSOCIAÇÃO BRASILEIRA DE CIÊNCIA POLÍTICA, 3, Niterói, 2002. Niterói: ABCP, 2002. 43p. 